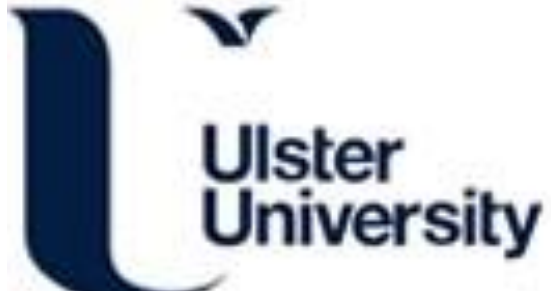

\section{Factors that influence participation in physical activity for anxiety or depression: a synthesis of qualitative evidence}

\begin{abstract}
McCartan, C., Yap, J., Firth, J., Stubbs, B., Tully, M., Best, P., Webb, P., White, C., Gilbody, S., Churchill, R., Breedvelt, J., \& Davidson, G. (2020). Factors that influence participation in physical activity for anxiety or depression: a synthesis of qualitative evidence. Cochrane Database of Systematic Reviews, (3), [CD013547]. https://doi.org/10.1002/14651858.CD013547
\end{abstract}

Link to publication record in Ulster University Research Portal

Published in:

Cochrane Database of Systematic Reviews

Publication Status:

Published (in print/issue): 04/03/2020

DOI:

10.1002/14651858.CD013547

\section{Document Version}

Publisher's PDF, also known as Version of record

\section{General rights}

Copyright for the publications made accessible via Ulster University's Research Portal is retained by the author(s) and / or other copyright owners and it is a condition of accessing these publications that users recognise and abide by the legal requirements associated with these rights.

\section{Take down policy}

The Research Portal is Ulster University's institutional repository that provides access to Ulster's research outputs. Every effort has been made to ensure that content in the Research Portal does not infringe any person's rights, or applicable UK laws. If you discover content in the Research Portal that you believe breaches copyright or violates any law, please contact pure-support@ulster.ac.uk. 


\section{Factors that influence participation in physical activity for anxiety or depression: a synthesis of qualitative evidence (Protocol)}

McCartan CJ, Yap J, Firth J, Stubbs B, Tully MA, Best P, Webb P, White C, Gilbody S, Churchill R, Breedvelt JJF, Davidson G

McCartan CJ, Yap J, Firth J, Stubbs B, Tully MA, Best P, Webb P, White C, Gilbody S, Churchill R, Breedvelt JJF, Davidson G. Factors that influence participation in physical activity for anxiety or depression: a synthesis of qualitative evidence. Cochrane Database of Systematic Reviews 2020, Issue 3. Art. No.: CD013547. DOI: 10.1002/14651858.CD013547.

www.cochranelibrary.com 
TABLE OF CONTENTS

HEADER 1

ABSTRACT

BACKGROUND

Figure 1.

OBJECTIVES

METHODS

ACKNOWLEDGEMENTS

REFERENCES

APPENDICES

CONTRIBUTIONS OF AUTHORS

DECLARATIONS OF INTEREST

SOURCES OF SUPPORT 
[Qualitative Protocol]

\section{Factors that influence participation in physical activity for anxiety or depression: a synthesis of qualitative evidence}

Claire J McCartan ${ }^{1}$, Jade Yap ${ }^{2}$, Joseph Firth ${ }^{3}$, Brendon Stubbs ${ }^{4}$, Mark A Tully 5 , Paul Best ${ }^{1}$, Paul Webb ${ }^{6}$, Chris White ${ }^{7}$, Simon Gilbody ${ }^{8}$, Rachel Churchill 9,10 , Josefien JF Breedvelt², Gavin Davidson ${ }^{1}$

${ }^{1}$ Centre for Evidence \& Social Innovation, School of Social Sciences, Education \& Social Work, Queen's University Belfast, Belfast, UK. ${ }^{2}$ Mental Health Foundation, London, UK. ${ }^{3}$ Division of Psychology \& Mental Health, University of Manchester, Manchester, UK. ${ }^{4}$ Institute of Psychiatry, Psychology and Neuroscience, Kings College London, London, UK. 5 Institute of Mental Health Sciences, School of Health Sciences, Ulster University, Newtownabbey, UK. ${ }^{6}$ Praxis Care, Belfast, UK. ${ }^{7}$ Mental Health Foundation, Glasgow, UK. ${ }^{8}$ Mental Health and Addiction Research Group, Department of Health Sciences, University of York, York, UK. ${ }^{9}$ Centre for Reviews and Dissemination, University of York, York, UK. ${ }^{10}$ Cochrane Common Mental Disorders, University of York, York, UK

Contact address: Claire J McCartan, Centre for Evidence \& Social Innovation, School of Social Sciences, Education \& Social Work, Queen's University Belfast, 6 College Park, Belfast, Northern Ireland, BT7 1LP, UK. c.j.mccartan@qub.ac.uk.

Editorial group: Cochrane Common Mental Disorders Group.

Publication status and date: New, published in Issue 3, 2020.

Citation: McCartan CJ, Yap J, Firth J, Stubbs B, Tully MA, Best P, Webb P, White C, Gilbody S, Churchill R, Breedvelt JJF, Davidson G. Factors that influence participation in physical activity for anxiety or depression: a synthesis of qualitative evidence. Cochrane Database of Systematic Reviews 2020, Issue 3. Art. No.: CD013547. DOI: 10.1002/14651858.CD013547.

Copyright $\odot 2020$ The Cochrane Collaboration. Published by John Wiley \& Sons, Ltd.

\section{A B S T R A C T}

This is a protocol for a Cochrane Review (Qualitative). The objectives are as follows:

Main objective: To identify the factors that create barriers or facilitate physical activity for people with a diagnosis of anxiety or depression from the perspectives of service users, carers, service providers and practitioners to help inform the design and implementation of interventions that promote physical activity.

The overall aim of this review is to identify, appraise, and synthesise qualitative research evidence on the barriers and facilitators to engaging in physical activity in general lifestyle settings or as part of an intervention designed to increase physical activity for people with anxiety and depression. This will allow us to identify factors that create barriers and facilitators of physical activity in this population to inform the development, design, and implementation of future interventions. We will also integrate the findings from the QES with the two associated effectiveness reviews (Cooney 2014; Larun 2006). We will communicate our findings to public health commissioners and other stakeholders. 


\section{B A C K G R O U N D}

Physical activity is good for you, but recent figures report that around 20 million adults (39\%) in the UK are physically inactive (British Heart Foundation 2017). Worldwide, 1400 million people do not meet the weekly recommendations for physical activity established by the World Health Organization (WHO) (WHO 2010). Physical inactivity increases the risk of many adverse health conditions and is a significant cause of premature mortality (Lee 2012). Conservative estimates suggest that in 2013, physical inactivity cost healthcare systems USD 53,800 million worldwide, contributed to USD 13,700 million in loss in productivity, and was responsible for GBP 13.4 million Disability Adjusted Life Years (DALYs) (Ding 2016). Being physically active has the potential to protect against depression (Schuch 2018) and lower the risk of breast cancer, colon cancer, diabetes, ischaemic heart disease, and ischaemic stroke. Larger reductions in risks, however, require significantly higher levels of physical activity than the minimum recommended level of 600 metabolic equivalent minutes per week (Kyu 2016). Recommended activity levels are higher for children and young people than adults (WHO 2012). High levels of sedentary behaviour in the youth population and its association with poorer physical and mental health is an area of concern (Hoare 2016). Sedentary behaviour, independent of physical activity, increases the risk of diabetes, cardiovascular disease, and cardiovascular and all-cause mortality (Wilmot 2012). While many public health strategies continue to promote the importance of physical activity, they are also beginning to acknowledge the role physical activity can play in promoting better mental health (NHS 2018).

Mental health problems contribute significantly to the overall disease burden worldwide and are major causes of disability, suicide, and ischaemic heart disease. People with mental ill health report lower levels of physical activity, and physical activity levels for those with anxiety and depression are considerably lower than the general population (de Wit 2010; Vancampfort 2017). People with anxiety and depression are at greater risk of chronic health conditions such as cardiovascular disease and obesity, and many have co-occurring medical conditions (comorbid conditions) caused by lifestyle behaviours (e.g. smoking, hazardous alcohol use, sedentary behaviour) that can lead to poor health outcomes (Cohen 2015; Strine 2008). People living with mental health conditions, including depression and anxiety, are also more likely to experience poverty (Bivanco-Lima 2007; Elliott 2016). The multi-dimensional effects of poverty can have an influence on judgement and decision-making about important lifestyle behaviours, including personal choices about exercise and nutrition (Mullainathan 2013; Wilkinson 2019).

While there may be a range of social and genetic determinants of mental health disorders (Cross-Disorder Group 2013; WHO 2014), being physically active can have positive benefits and may help improve the mental and physical health of those with some disorders (Ströhle 2008). Physical activity can improve self-esteem (Firth 2016a; Lubans 2016), cognitive functioning and help reduce symptoms (Ashdown-Franks 2019; Firth 2016a; Gerber 2014; Stubbs 2018; WHO 2010). Based on secondary analysis of available data, physical activity has been shown to be potentially as effective as many drug interventions (e.g. statins, beta blockers) at preventing cardiovascular disease mortality (Naci 2013). Physical activity is cited in the National Institute for Health and Care Excellence (NICE) clinical guidelines as a potential treatment option for people with persistent subthreshold depressive symptoms or mild to moderate depression (NICE 2018) and generalised anxiety disorder and panic disorder (NICE 2019). The European Psychiatric Association (EPA) has also made clinical practice recommendations for physical activity as a treatment for mild-moderate depression (Stubbs 2018). Not engaging in sufficient physical activity is also a risk factor for developing depression and anxiety in children and adults (AbuOmar 2004; Goodwin 2003; Motl 2004; Reed 2009; Schuch 2018; Zahl 2017).

A number of barriers to physical activity are identified in the qualitative literature. They include low levels of motivation, poor self-perception and inexperience/lack of competence (Cole 2010; Glowacki 2017). Practical issues such as cost (unemployment) and access (transport) can create barriers (Wynaden 2012). Aspects that help facilitate physical activity include the recognition of the psychological and physical benefits (Firth 2016b), and good social and peer support networks (Schuch 2016). Gaining mastery and growing competency also encourages people to continue participation (Carless 2008; Firth 2016b; Hodgson 2011). For young people, many of these barriers and facilitators are shared (e.g. cost, time, transport, infrastructure, social support, motivation), but additional barriers may be faced (Martins 2015). These can include negative associations with the competitive nature of physical activity within schools and the pressure of winning/losing in front of their peer group or vested adults (Yungblut 2012). Activity often reduces as children age (Dumith 2011) and the transition periods, between primary to high school (10-12 years old) and high school to labour market entry (16-18 years old), may be significant (Bélanger 2011; Coleman 2008).

\section{Anxiety and related disorders}

Anxiety disorders are typically characterised by persistent and excessive worry and can have a range of potentially debilitating physical and psychological symptoms (Lader 2015). These can present as excessive fear, muscle tension, fatigue, irritability, cautious or avoidant behaviours, and related behavioural disturbances and must have a duration of at least six months to meet the criteria for diagnosis (APA 2013). There are a range of different types including agoraphobia, generalised anxiety disorder (GAD), panic disorder and social anxiety disorder and other phobic disorders, and disorders associated with child populations (separation anxiety and selective mutism). Associated conditions also include trauma- and stressor-related disorders (e.g. post-traumatic stress disorder (PTSD) or acute stress disorder) and obsessive-compulsive and related disorders (e.g. obsessivecompulsive disorder (OCD)) (Kupfer 2015).

Anxiety disorders are common; lifetime prevalence is estimated to be as high as $33.7 \%$ of the population (Bandelow 2009), with the global prevalence rate estimated to be $3.6 \%$ (WHO 2017). A recent UK prevalence survey reported that $7.2 \%$ of $5-19$ year olds had an anxiety disorder (Sadler 2017). They are more common among females than males (WHO 2017). The age of onset is typically in childhood or adolescence, and the course is often chronicrecurrent (Kessler 2009). Prevalence rates do not vary greatly between age groups, but there is a trend towards lower prevalence among older people (WHO 2017). Anxiety disorders are the sixthleading cause of disability globally and are associated with an elevated risk of comorbid cardiovascular diseases (Batelaan 2016; Roest 2012). They are highly comorbid with each other and other psychiatric conditions (Bandelow 2009; Noyes 1998), particularly 
mood disorders (Maser 1990) and autistic spectrum disorders in childhood and adolescence (de Bruin 2007; Kerns 2015; van Steensel 2011). Impairment of quality of life is comparable to other chronic medical conditions like diabetes (Andrews 1998; Kessler 1999; Olfson 1997; Rubin 2000). Twin studies have identified that genetics generate a significant risk of developing a disorder along with individual environmental factors (Hettema 2001). Research has also shown that individuals engaging in low levels of physical activity have a higher chance of experiencing anxiety (Stubbs 2017).

\section{Depression}

Depression, often comorbid with anxiety (Sartorius 1996), can have a range of physical and psychological symptoms. It can affect a person's mood, generate negative feelings of self-concept, and create regressive and self-punitive thoughts; and may also manifest changes to the body (somatic changes) and reduce motivation and energy levels (Beck 2009). At its most extreme, depression can lead to suicide (Reddy 2010; WHO 2017). An individual must experience five or more symptoms during a two-week period including at least one symptom of depressed mood or loss of interest or pleasure. Other symptoms are debilitating and can negatively impact on work, social, family, academic, and other important areas of functioning. These symptoms include: significant weight loss when not dieting or weight gain; a noticeable slowing down of thought and reduction in physical movement; fatigue; feelings of worthlessness or excessive guilt; diminished ability to think or concentrate or indecisiveness; and recurrent thoughts of death and suicidal ideation without a specific plan (APA 2013). Depressive disorders include two main subcategories: major depressive disorder (MDD)/depressive episode and persistent depressive disorder, a persistent or chronic form of mild depression.

In 2015, the proportion of the global population estimated to have depression was $4.4 \%$; it is more common in females $(5.1 \%)$ than in males (3.6\%) (WHO 2017). A recent UK prevalence survey reported that $2.1 \%$ of 5-19 year olds had a depressive disorder (Sadler 2017). Depression is the leading cause of disability measured by Years Lived with Disability (YLDs) and is the fourth-leading contributor to the global burden of disease (WHO 2017). Depression results from a complex interaction of social, psychological, and biological factors. Epidemiologic studies show that about $50 \%$ of the risk of depression is genetic (Fava 2000; Sanders 1999), but nongenetic factors are also considered to be important. Adverse life events, stress, or viral infections can increase the risk of developing depression, and the disorder is also prevalent in other medical conditions such as endocrine (relating to the glands that make and release hormones into the blood) and cardiovascular diseases, Parkinson's disease, head injuries, some cancers, asthma, diabetes, and stroke (Nestler 2002; WHO 2017). Lower levels of physical fitness have been observed in patient groups with depression (Martinsen 1989) and an association has been established between sedentary lifestyles and depression in both adults and adolescents (Buckworth 2002; Sund 2004).

\section{Description of the topic}

Physical activity is defined as any bodily movement produced by the contraction of skeletal muscle that increases energy expenditure above a basal level (Caspersen 1985). This includes walking, cycling, sports, and other active forms of recreation (e.g. dance, gardening, yoga, Tai Chi). Exercise, a subcategory of physical activity, is defined as planned, structured, and repetitive physical activity that is aimed at improving or maintaining one or more components of physical fitness (Caspersen 1985; Garber 2011; US Dept of HHS 2008). Physical inactivity is a global problem, and understanding the reasons behind the motivation to be active forms part the WHO's 2018-2030 technical package to increase physical activity (WHO 2018); however, activity rates are much lower for people with depression and anxiety than for the general population (Martinsen 1989). Cross-sectional, community-based data from the World Health Survey established that the prevalence of low physical activity in those with and without anxiety was $22.9 \%$ versus $16.6 \%(P<0.001)$ and that individuals engaging in low physical activity had $1.32(95 \% \mathrm{Cl}=1.17$ to 1.47$)$ times higher odds for anxiety than those with higher physical activity levels (Stubbs 2017). A systematic review and meta-analysis of physical activity and sedentary behaviour in people with major depressive disorder found that adults with MDD engaged in low levels of physical activity (SMD $=-0.25,95 \% \mathrm{Cl}=-0.03$ to 0.15$)$ and high levels of sedentary behaviour (SMD $=0.09,95 \% \mathrm{Cl}=0.01$ to 0.18) compared with controls (Schuch 2017). Further exploration of the bidirectional relationship between anxiety and depression and physical activity is necessary (Azevedo Da Silva 2012), but it is clear that physical activity has the potential to play a role in both the prevention and treatment of mental health conditions whilst generating positive benefits for general physical health.

Physical activity is relatively easy to deliver in home-based, clinical, or community settings. It carries a relatively low risk of negative side effects (Wright 2009), although these can include addiction to physical activity, 'muscle dysmorphia', and associated risks with the use of anabolic-androgenic steroids, intense exercise and mood disturbances and overtraining syndrome (Peluso 2005). A number of methodological shortcomings in randomised controlled trials have made it difficult to assess how effective it is in a clinical setting (Krogh 2011), and two systematic reviews concluded that evidence was lacking for the optimum type, frequency, duration, and setting for effective interventions (Cooney 2014; Stanton 2014). Bailey and colleagues' systematic review of physical activity for treating depression in adolescents and young adults also drew similar conclusions but recommended that physical activity was a promising and acceptable intervention for this age group (Bailey 2018). A more recent meta-review informing the European Psychiatric Association (EPA) guidelines for physical activity did recommend, on the basis of good-quality evidence, that an intervention delivered 2 to 3 times per week of supervised aerobic and/or aerobic and resistance training of 45 to 60 minutes duration would achieve optimal outcomes and less attrition (Stubbs 2018). Studies evaluating the efficacy of physical activity interventions as treatment for anxiety or depression disorders, or both, generally find a reduction in anxiety or depressive symptoms (Carek 2011; Jayakody 2014), and that exercise may be as effective as antidepressant treatment (Stubbs 2018). The overall health benefits of being more active can also have a positive impact on quality of life and well-being. Physical activity is increasingly used in consultant, allied health professional, and general practitioner referrals as a treatment option or as a complementary therapy (Price 2018), and exercise referral schemes are outlined in public health guidance by NICE and recommended as treatment by the EPA (NICE 2014; Stubbs 2018).

Many factors can create barriers or facilitators in physical activity, and these can be increased for people experiencing anxiety and depression. Better understanding of what motivates or inhibits 
individuals to be physically active could help practitioners to work more effectively with this client group (Wheeler 2018) and help to establish realistic exercise goals within a treatment programme (Ehrlich 2015; Young 2017). Although there is substantial evidence for the positive impact that physical activity has on mental health (Penedo 2005), some criticism has been levelled at the potential risk of bias, lack of control groups, and results from randomised controlled trials that are neither clinically nor statistically significant (Cooney 2014; Kvam 2016). However, more recent meta-reviews have reported more robust evidence of the benefits of physical activity for depression and anxiety (AshdownFranks 2019; Stubbs 2018).

This qualitative evidence synthesis (QES) will synthesise the qualitative evidence for the factors that create barriers or facilitators of physical activity for people with anxiety or depression and indicate what may help people with lived experience of these conditions to be more active in order to benefit their physical and mental health. This QES will complement another that will consider the facilitators and barriers for people with bipolar disorder (McCartan (in press)).

\section{Why is it important to do this synthesis?}

Very low levels of physical activity remain a public health concern. Understanding more about the factors that create barriers or facilitate physical activity could help inform the design and development of interventions to improve the physical and mental health of children, young people and adults with anxiety and depression. This QES will use the Health Belief Model (HBM) to examine these factors and outline what may help people with lived experience of anxiety or depression to be more physically active. The HBM is a theory of behaviour change developed to explain and help predict health-related behaviours, particularly related to the uptake of health services. The HBM has been used as a conceptual framework in health behaviour research since the 1950s to explore why people fail to participate in programmes designed to prevent and detect disease (Glanz 2010; Hochbaum 1958; Rosenstock 1960; Rosenstock 1974). It can help explain the change and maintenance of health-related behaviours and has been used as a guiding framework for many health-behaviour interventions (Jones 2014). This QES will examine how factors such as age, gender, class, ethnicity, mental health diagnosis and co-morbidities affect participation. It will consider people's perceptions about their physical and mental health needs and identify the barriers and facilitators to physical activity. It will also consider which cues influence people to take action. It will seek to understand why interventions work (or not), why people engage (or not) and how carers, service providers and health professionals view, support or influence treatment engagement.

A QES can help to identify the factors influencing the success of interventions including the attitudes and experiences of service users, their carers, service providers, and the health professionals involved in their care. A number of intervention effectiveness reviews have concluded that exercise is an acceptable intervention for anxiety and depression, drawing evidence from measures including treatment attendance/completion, self-esteem and quality of life scales, and adverse event metrics (Cooney 2014; Meekums 2015; Stubbs 2016), but this evidence tells us little about the motivations, barriers, and facilitators to engaging in physical activity. Meta-analyses have also explored factors associated with lower attrition, including interventions supervised by physiotherapists or exercise physiologists, inpatient settings, those already taking antidepressant medication; however, we also know that people with anxiety and depression face a range of barriers to regular physical activity including higher depressive symptoms, higher body mass index (BMI), somatic comorbidities, and lower self-efficacy (Vancampfort 2015), and early dropout can be a particular problem (Cooper 2015). Firth and colleagues conducted a systematic review and meta-analysis of quantitative data on the motivating factors and barriers for exercise in serious mental illness (Firth 2016b), but less is known about findings from qualitative studies. Developing a more nuanced understanding of how accessible physical activity is for people with anxiety and depression could bring important knowledge to the design, development, and implementation of interventions. QES provides the opportunity to add rich and contextual data and contribute to the knowledge base to help understand why and how best to increase physical activity levels among people with anxiety and depression. It will provide qualitative evidence to complement the findings of two Cochrane Reviews that have investigated the effectiveness of Exercise for depression (Cooney 2014) and Exercise in prevention and treatment of anxiety and depression among children and young people (Larun 2006). These reviews concluded that exercise is moderately more effective than a control intervention for reducing symptoms of anxiety and depression, but the evidence is limited in both quantity and quality. A QES will provide greater insight exploring the lived experience of service users, carers, service providers, and practitioners to help highlight common beliefs, misconceptions and fears, and benefits of physical activity participation.

\section{How the intervention might work}

Physical activity has been shown to help prevent and reduce symptoms of anxiety and depression (Asmundson 2013; Martinsen 2008; Wright 2009), and has contributed to remission in some patients (Blumenthal 2007). Physical activity may help to alleviate symptoms in a number of different ways. It is hypothesised that it may stimulate the serotonergic system and increase feelings of well-being (Basso 2017), and can have a significant antidepressant effect (Josefsson 2014; Schuch 2016). It is often argued that physical activity results in positive neurobiological effects (e.g. increased levels of atrial natriuretic peptide (ANP) or brain natriuretic peptide (BNP)) and the release of endorphins, although evidence for this is lacking (Dishman 2009). The biological mechanisms are still not fully understood, but evidence points to a complex interaction of hormones, neurotrophones, inflammation biomarkers, oxidative stress, and cortical plasticity and activity (Schuch 2016). Physical activity can also boost mood in anxious or depressed patients by reducing fatigue (Herring 2011), improving sleep and helping with insomnia (Martiny 2012; Rethorst 2013). Being physically active can also contribute to physical changes (Bartels 2018), which in turn can increase self-esteem, improve feelings about body image and positive perceptions of oneself. Physical activity can help deliver positive social experiences (Carless 2008); group-based activities can extend social networks and support systems for people who may have felt isolated because of their illness and feelings of low self-worth. Being active has also been linked to increased ratings of quality of life, pleasure, and motivation (Carta 2008; Greer 2016; Stubbs 2018). Improvements in cognitive functioning have also been observed (Mandolesi 2018). Evidence has also been reported for the effectiveness of physical activity as an adjunct 
to pharmacotherapy, Carneiro 2015; Kvam 2016, or therapeutic interventions such as cognitive behaviour therapy (Hallgren 2016).

Increasing physical activity to prevent and treat anxiety and depression will often require specific behavioural changes (such as a decrease in sedentary behaviour and an increase in physical exertion). We want to understand how people with anxiety and depression adopt or reject positive physical activity behaviours. Applying a theoretical model of behaviour change can help understand the sequence of these mechanisms and identify what factors trigger positive change. This will identify which physical activity interventions are likely to be effective; to date, insufficient attention has been given to analysing behaviour change theories as a starting point for developing an intervention (Johnston 2008).

The Health Belief Model (HBM) consists of six key concepts that predict why people will take action to prevent, screen for, or control illness conditions (Champion 2008), and acknowledges the range of modifying variables such as demographic, socio-economic, and structural factors that may also influence behaviour. It has been validated in a range of domains and populations (Carpenter 2010; Janz 1984). Although this model has its critics (Orji 2012), it can be a useful way to frame the barriers and facilitators for physical activity in anxiety and depression. The theoretical model identifies six domains that categorise the potential threats and expectations of a health behaviour and consider the cues or stimuli that will lead to action. Four additional domains were developed by Orji and colleagues to improve its predictive power (Orji 2012): concern for appearance, consideration of future consequences, perceived importance, and self-identity. The six key concepts are as follows.
1. Perceived susceptibility: the perceived risk of getting a condition or disease. This will include a person's awareness and acceptance of their mental health diagnosis and any comorbid physical health needs.

2. Perceived severity: the probability that a person will change their behaviour to avoid the consequence depends on how serious a condition they consider the consequence to be. How serious is the physical health condition when mental health is often the primary diagnosis? Does the service user understand the physical health risks associated with their mental health condition?

3. Perceived benefits: the perception of the good things that could result from participating in specific behaviours. What is in it for the participant? People do not want to give up something they enjoy if they do not get something in return.

4. Perceived barriers: the perception of the difficulties and costs of performing behaviours. This could relate to both intrinsic (shame, stigma, perceived lack of ability, lack of appropriate skills and knowledge) and extrinsic factors (cost, equipment, impact of medication, comorbid conditions).

5. Cues to action: exposure to factors that lead to action: public health messages, relationships with healthcare professionals, support from social/family systems, physical health checks, reminders, telemonitoring.

6. Self-efficacy: confidence in one's ability to take action. Low levels of motivation and self-esteem.

See Figure 1. 
Figure 1. Health Belief Model for participation in physical activity for people with anxiety and depression

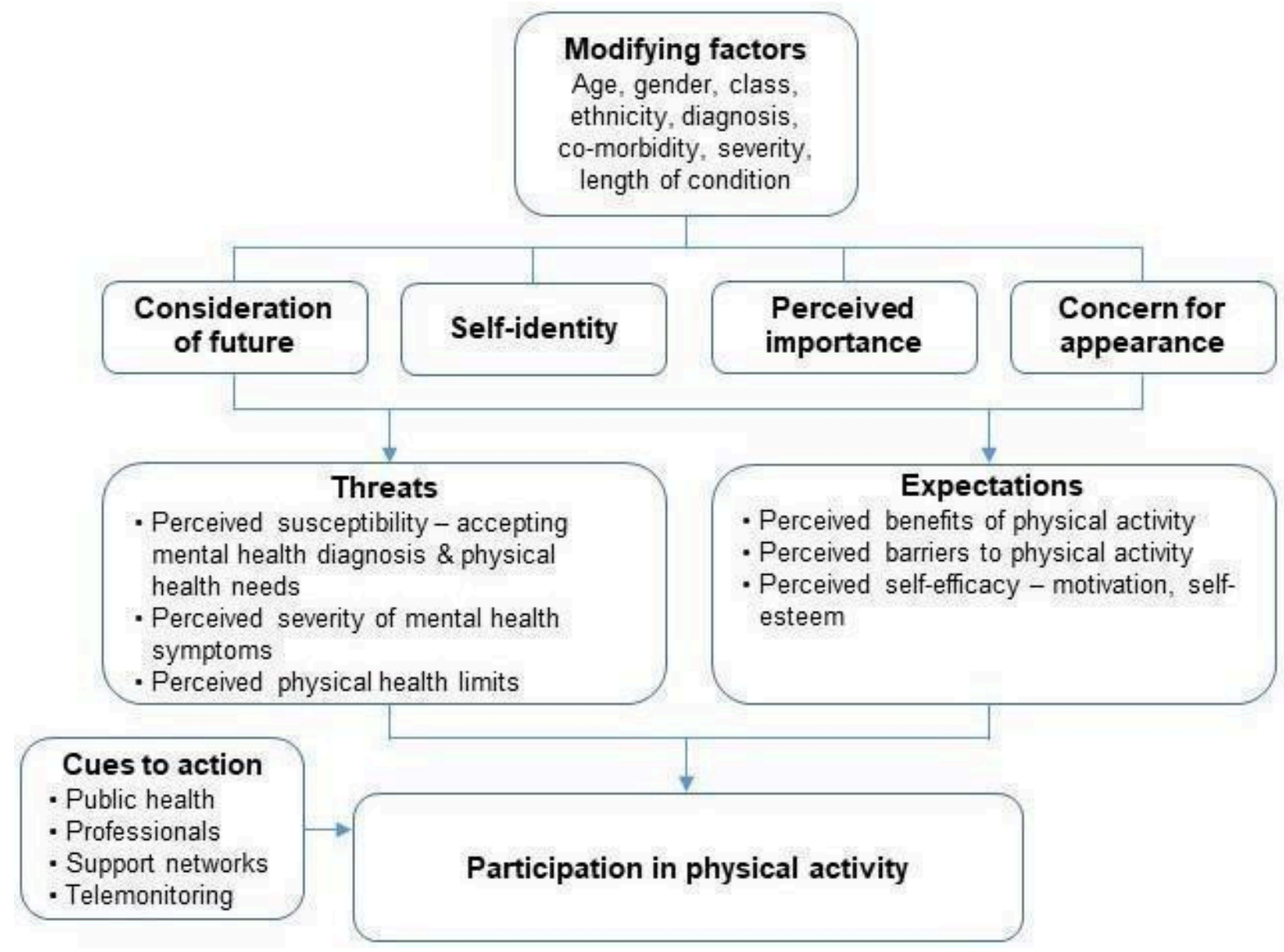

\section{Perceived susceptibility and severity of physical health problems}

Perceptions about the susceptibility and severity of physical health problems in anxiety and depression may be affected by current healthcare delivery. People with severe and enduring mental health problems may not be aware of all of their physical health needs these can be neglected (Fagiolini 2009; Kisely 2007; Mitchell 2009; Tidemalm 2008) and there are inequalities in access to, use and delivery of healthcare in this population (Lawrence 2010; de Hert 2013). People with severe mental illness are less likely to receive health promotion interventions and other forms of preventive care such as routine cancer screening (Naylor 2016) and smoking cessation treatments (Gilbody 2019).

\section{Perceived benefits}

Improvements in general physical health, fitness and body image and the psychological benefits of improved sleep, stress reduction, mood management and increased self-confidence have all been identified as perceived benefits (Firth 2016b). Positive feelings relating to a sense of achievement, acquiring new skills and developing mastery have also been cited in the literature (Carless 2008; Hodgson 2011; Wynaden 2012).

\section{Perceived barriers}

Many of the qualitative studies that consider the perceived barriers to engaging in physical activity cover intrinsic mechanisms that hinder involvement. These include low motivation or energy levels, which can often be symptomatic of an illness (Cole 2010; Firth 2016b), or sometimes a side effect of a particular medication or other health characteristics including high BMI or cigarette use. Psychological factors including embarrassment, poor perception of self, and guilt can also have a negative impact (Glowacki 2017), as well as general anxiety for social reasons, lack of experience, or perceived lack of ability or poor body image (Cole 2010; Firth 2016b). Some studies also consider the counter effects of exercise participation; where patients do not successfully initiate or maintain an exercise activity, this can negatively affect their self-esteem (Searle 2012). Patient expectations of the impact of raised activity levels may also need to be managed (Jones 2005). Physical activity may not have the desired affects for everyone; a review by Schuch and colleagues found that half of patients with mild depressive disorder did not respond to exercise (Schuch 2016). Other issues to consider relate to practical difficulties including navigating public transport, high cost, and having no one to accompany them (Wynaden 2012).

\section{Cues to action}

Cues to action such as having appropriate social support systems in place can help encourage people to become more active and can also have benefits beyond the intervention setting (Carless 2008); 
they can also help tackle patients' motivation and anxiety that may have prevented them from engaging in the past. This can be achieved over the phone or by other means such as telemonitoring as well as by face-to-face contact (Argent 2018; Crone 2008; Searle 2014). Having someone to help familiarise them with the setting and activities at the start of a programme can also be of great value (Firth 2016b). Having peer support systems in place can help people engage (Firth 2016b; Oman 2003), and programmes that promote physical health, fitness, and body image outcomes can motivate involvement (Firth 2016b).

\section{Self-efficacy}

Higher levels of self-efficacy evident in people who are already physically active or involved in sport are more likely to benefit (Dishman 1985), as will people who have higher levels of selfesteem, perceived physical condition and body attractiveness.

\section{OB JECTIVES}

Main objective: To identify the factors that create barriers or facilitate physical activity for people with a diagnosis of anxiety or depression from the perspectives of service users, carers, service providers and practitioners to help inform the design and implementation of interventions that promote physical activity.

The overall aim of this review is to identify, appraise, and synthesise qualitative research evidence on the barriers and facilitators to engaging in physical activity in general lifestyle settings or as part of an intervention designed to increase physical activity for people with anxiety and depression. This will allow us to identify factors that create barriers and facilitators of physical activity in this population to inform the development, design, and implementation of future interventions. We will also integrate the findings from the QES with the two associated effectiveness reviews (Cooney 2014; Larun 2006). We will communicate our findings to public health commissioners and other stakeholders.

\section{METHODS}

\section{Review author reflexivity}

Throughout the data synthesis, the review authors will reflect on their own positions and assess how these could influence the study design, search strategy, inclusion decisions, data extraction, analysis and synthesis, and interpretation of the findings. We are aware of our own professional backgrounds, and one of the strengths of the team is the diversity of disciplines it includes (including advocacy, mental health social work, psychiatry, physiotherapy, service user participation, service delivery, sports psychology), alongside clinical or research experience, or both. The review authors have multiple perspectives, but all support the principle that being physically active can have benefits for both physical and mental well-being and that intervention design and implementation strategies should be sensitive to the needs and experiences of service users, carers, service providers, and healthcare professionals. Progress will be discussed regularly and decisions that are made will be explored critically. As lead author, $\mathrm{CMCC}$ will keep a reflexive journal throughout the process to document and reflect on progress and record discussions and decisions made. Stakeholder consultation will also provide additional opportunities to reflect on review author decisions.

\section{Criteria for considering studies for this synthesis}

\section{Types of studies}

This is a systematic review of qualitative primary studies designed to increase physical activity participation in order to reduce the symptoms of anxiety or depression (reduction in feelings of depression, anxiety). We will include primary studies that use qualitative study designs such as ethnography, phenomenology, case studies, grounded theory studies, and qualitative process evaluations. We will include studies that use both qualitative methods for data collection (e.g. focus group discussions, individual interviews, observation, diaries, document analysis, and open-ended survey questions) and qualitative methods for data analysis (e.g. thematic analysis, framework analysis, grounded theory). We will exclude studies that collect data using qualitative methods but do not analyse these data using qualitative analysis methods (e.g. open-ended survey questions where the response data are analysed using descriptive statistics only). We will include studies irrespective of their publication status and language of publication. Mixed-methods studies where qualitative findings can be extracted separately will also be included.

A second element to the synthesis will link findings from two effectiveness reviews to the QES and explore in more detail some of characteristics of the acceptability of interventions and effect on symptoms reported in Cochrane Reviews for depression and anxiety (Cooney 2014; Larun 2006). The review by Cooney and colleagues considered treatment adherence, completion, and quantitative ratings of quality of life and self-esteem, but also examined other barriers and facilitators. Both effectiveness reviews also reported changes in symptoms and adverse events. The findings from these two reviews will be integrated with the QES findings.

We will not exclude any studies based on our assessment of methodological limitations, but will utilise this information to assess our confidence in the synthesis findings.

\section{Topic of interest}

We will include studies that focus on the experiences and attitudes of service users, caregivers, service providers, and healthcare professionals towards physical activity for anxiety and depression. We will look for evidence of the factors that create barriers to or facilitate participation in physical activity. We will include all approaches to increasing physical activity, supervised or unsupervised, in individual or group settings for people with anxiety or depression for physical or mental health benefits. We will exclude yoga, Tai Chi, and other mind-body interventions because although these involve physical activity, the therapeutic benefits are theoretically derived from components of the intervention that are distinct from the physical activity itself. For instance, yoga is closely related to meditation and mindfulness, which share common practices and therapeutic principles grounded in religion/ spirituality that may offer benefits distinct from a purely physical activity intervention (Breedvelt 2019).

\section{Types of participants}

We will include studies where the primary focus is the experience of children, young people or adults (there will be no age restrictions) with a primary clinical diagnosis (Diagnostic and Statistical Manual of Mental Disorders, 5th edition (DSM-5) (APA 2013)/International 
Statistical Classification of Diseases and Related Health Problems, 10th Revision (ICD-10)(WHO 1992)) of depression (ICD-10 codes F32-39), anxiety or related disorders (ICD-10 codes F40-43, F93-94), their carers, service providers, and associated health professionals, as follows.

\section{- Agoraphobia}

- Generalised anxiety disorder (GAD)

- Panic disorder

- Selective mutism

- Separation anxiety

- Social anxiety disorder (SAnD)

- Social phobia

- Obsessive-compulsive disorder (OCD)

- Post-traumatic stress disorder (PTSD)

- Major depressive disorder (MDD)

- Seasonal affective disorder (SAD)

- Dysthymia

- Postnatal depression

- Specific phobias

- Treatment Resistant Depression (TRD)

OCD and PTSD, although no longer categorised as anxiety disorders under DSM-5 (Kupfer 2015), will be included. We will exclude mental health conditions that do not have a clinical diagnosis and age-related conditions (i.e. conditions or diseases that increase in incidence/prevalence with ageing such as dementia). We will include participants with other comorbid conditions such as cardiovascular disease, stroke, and diabetes or other mental health conditions as long as there is a primary diagnosis of depression or anxiety. We will include studies that provide qualitative evidence of the views and experiences of service users, carers, service providers, and healthcare professionals. Participants may be service users, paid (care assistants, home helps) or unpaid carers (including family members, friends), service providers (e.g. voluntary and community sector organisations delivering mental health services), and healthcare professionals (e.g. social workers, general practitioners, community mental health nurses, occupational therapists, physiotherapists, key workers, consultant psychiatrists).

\section{Search methods for identification of studies}

\section{Electronic searches}

We will develop search strategies for each database, using guidelines developed by the Cochrane Qualitative Research Methods Group, Harris 2008, for searching qualitative evidence as well as modified versions of the search developed for the two related effectiveness reviews, Cooney 2014; Larun 2006, plus other (more recent) systematic reviews and meta-analyses. We won't apply any restrictions on date, language or publication status to the searches.

\section{Search terms}

\section{(i) Preliminary searches}

Identifying search terms for the intervention, those which address the barriers and facilitators to enable people with anxiety or depressive disorders to increase their levels of physical activity and/or start exercising are difficult to identify from scratch.

We will perform an initial search on the following databases:

- Ovid MEDLINE (1946 onwards) (Appendix 1);

- Ovid PsycINFO (all years).

The preliminary searches will be based on population (anxiety/ depressive disorders) combined with broad, top-level terms for the intervention (barriers/facilitators) and a sensitive list of terms for outcome (physical activity).

Two review authors will screen the search results to identify relevant primary studies and reviews (quantitative and qualitative). The review authors will screen the bibliographic records, looking at the title words, author-assigned keywords, key phrases, search strings, and subject headings for the intervention. We will use these terms to enrich the remaining searches (and if necessary amend the preliminary MEDLINE/PsycINFO searches, as appropriate). We will also run a search for systematic reviews and meta-analyses of effectiveness reviews (targeting exercise for the treatment or prevention of affective disorders) and check the included studies for qualitative (follow-up) data.

\section{(ii) Main searches}

We will conduct additional searches of the following databases:

- Ovid Embase (1980 onwards);

- Wiley Cochrane Library (current issue);

- Web of Science Science Citation Index Expanded (SCIE) (all available years);

- Web of Science Social Science Citation Indexes (SSCI) (all available years);

- EBSCO Cumulative Index to Nursing and Allied Health Literature (CINAHL) (1980 onwards);

- ProQuest International Bibliography of the Social Sciences (IBSS) (1951 onwards);

- ProQuest Sociological Abstracts (1952 onwards);

- EBSCO SPORTDiscus (1982 onwards);

- NCBI PubMed NOT MEDLINE subset (all years).

- Social Policy and Practice

The additional searches will be based on the following structure: population (anxiety/depressive disorders) AND intervention (barriers or facilitators) AND outcome (physical activity) OR population and types of intervention 'enabling' exercise.

\section{(iii) Searching other resources}

We will check the reference lists of effectiveness studies included in intervention reviews in order to identify any qualitative studies that are linked to these studies.

We will contact the authors of included studies to clarify reported published information and to seek unpublished results/data. We will contact researchers with expertise relevant to the synthesis topic to request potentially eligible studies.

Once records have been screened and studies selected for inclusion, we will perform forward and backward citation searching. We will check the reference lists of all included 
studies and relevant systematic reviews to identify additional studies missed from the original electronic searches (for example unpublished or in-press citations). We will use the Web of Science and Google Scholar to conduct forward citation searching. We will also perform cluster searching (Booth 2013) and use PubMed's related references feature.

\section{(iv) Grey literature}

We will conduct a grey literature (literature that is not published in sources such as books or journal articles) search to identify studies not indexed in the databases listed above.

- OpenGrey (www.opengrey.eu/)

- ProQuest Dissertations \& Theses Global

- DART-Europe E-theses Portal (www.dart-europe.eu/)

- EThOS - the British Library's e-theses online service (ethos.bl.uk/)

- Open Access Theses and Dissertations (oatd.org)

\section{Stakeholder involvement}

Stakeholders will be involved before, during, and after the review. We will draw on the expertise of an Advisory Group of people with lived experience and professionals working in the area who will be involved in the problem-framing stage, and who will be consulted to expand the search to include grey literature, relevant websites, and regarding knowledge of programmes that have been delivered.

\section{Data collection, management, and synthesis}

\section{Selection of studies}

Records identified from different sources will be imported into EndNote and duplicates removed (EndNote 2019). Two review authors from a team of six (JB, PB, GD, CMcC, PW, JY) will independently screen the title and abstracts of the retrieved records to determine their potential eligibility. We will retrieve the full text of all papers identified as potentially relevant by one or both review authors. Two review authors will then independently assess these papers for inclusion in the review. Any disagreements will be resolved via discussion or by seeking a third review author's opinion when necessary. Where appropriate, we will contact the study authors for further information. We will include any qualitative 'sibling' studies from the two relevant effectiveness reviews (Cooney 2014; Larun 2006), and link factors that created barriers or facilitators using subgroup analysis where possible (Noyes 2016).

We will include a table listing the studies excluded from our synthesis at the full-text stage and the main reasons for exclusion.

Where the same study, using the same sample and methods, is presented in different reports, we will collate these reports so that each study, rather than each report, is the unit of interest in the review.

We will include a PRISMA flow diagram illustrating our search results and the process of screening and selecting studies for inclusion.

\section{Translation of languages other than English}

For papers that are published in a language not understood by the review authors (i.e. languages other than Dutch, French, German,
Italian, Portuguese, and Spanish), the abstract will be subject to initial translation through open source software (Google Translate). If this indicates inclusion, or if the translation is inadequate to permit a decision, we will ask members of the multilingual networks associated with the research teams of the review to translate the full text. If this cannot be done, we will categorise the study as 'awaiting classification' to ensure transparency in the review process.

\section{Sampling of studies}

We will select a sample of studies if more than 40 studies are eligible for inclusion. We will use a purposive sampling approach and apply maximum variation sampling with the aim of extracting the broadest possible variation within the eligible studies (Patton 2002). This approach has been demonstrated successfully in two other QES reviews (Ames 2017; Karimi-Shahanjarini 2019), and can help deal with large quantities of data that could potentially impair the quality of analysis (Glenton 2013). Included studies will be selected based on their direct relevance and which address the contextual factors important for the review question including the perspective, population, the phenomenon of interest and the setting. We will also apply the GRADE-CERQual guidance to assess the contextual factors and relevance of the evidence to inform the sampling of studies (Noyes 2018).

\section{Data extraction}

Two review authors from a team of four (GD, CMCC, JY, PW) will independently extract data from each included study using a data extraction form (see Appendix 2). The relevance of the research will be assessed using GRADECERQual The data extraction template is based on the HBM, which includes specific information about: modifying factors (age, gender, socio-economic status, ethnicity, diagnosis, comorbidity, severity or length of condition); perceived seriousness and susceptibility (consideration of future, self-identity, perceived importance, concern for appearance); threats; expectations; cues to action; and outcomes relating to participation in physical activity. Any theoretical frameworks used to analyse the data will also be recorded. Where additional themes are identified, these will be discussed by the review team. We will also extract additional contextual and methodological information from the included studies detailing information about the country, study design, setting, population, participants, and a description of the intervention (if delivered) (logic model, number, frequency and duration of sessions). We will record methods used to identify and recruit the sample, data collection and analysis, relevant quantitative findings, supporting quotations, conclusions, and any relevant tables, figures, or images. We will agree a final a priori framework using the Template for Intervention Description and Replication (TIDierR) checklist and guide (Hoffman 2014) and data will be coded from the included studies against this framework. Any disagreements will be resolved by discussion or by seeking the views of a third review author when necessary.

\section{Data synthesis}

We will use an adapted version of the HBM (Figure 1) as a basis for a 'best fit' framework synthesis (BFFS) approach to analyse and synthesise qualitative evidence (Booth 2015; Booth 2016; Carroll 2013). The HBM has been used to explore health beliefs and physical activity in a range of populations, Gristwood 2011; Hosseini 2017; Kasser 2012, and informed the development of physical activity interventions (Shao 2018). The selection of the 
HBM drew on the Cochrane Methods guidance for selecting a theory for complex intervention reviews (Noyes 2015); the model has the ability to consider complex interventions and has been validated and used in other systematic reviews. The review team are also familiar with its application.

We chose the BFFS approach because it can be useful for designers of interventions, policymakers, and practitioners and is capable of describing and interpreting what is happening in a particular setting using a pragmatic approach to integrating data and engaging with existing theory (Booth 2016). It can be used to analyse and synthesise both primary and secondary data and to integrate quantitative and qualitative data (Booth 2015). However, should we deem the BFFS approach unsuitable as we begin to extract and code the data, we will use an alternative inductive thematic synthesis approach (Thomas 2008). BFFS requires the preliminary identification of a priori themes in order to map data from studies. Where any relevant data do not translate into the preexisting constructs of the HBM, additional themes will be created as needed based on the emerging data. We will tailor the theoretical model to develop a 'best fit' theory (Noyes 2015). The HBM will provide a basis for the synthesis but will be "built-upon, expanded upon, reduced or added to by these new data" as described by Carroll and colleagues (Carroll 2011, p.4). Data extraction and categorisation or coding of data will be discussed and agreed upon by the team at regular intervals. How modifying factors such as gender, race, and age affect participation will be discussed regularly to build the framework model. The BFFS approach will test the a priori framework and re-test it using sensitivity analysis to explore how different modifying factors such as gender, race, age, and study quality affect the interpretation of the data (Booth 2015). It will also be important to capture the range of different perspectives (service user, carer, service provider, health professional) and assess whether an alternative explanation of engagement or nonengagement in physical activity is presented in the data, and add this to the final model if appropriate. A consensus will be reached on the final list of themes.

The BFFS follows seven steps of synthesis, as follows:

1. identify a clearly formulated review question;

2. (a) systematically identify relevant primary research studies; and (b) identify relevant ('best fit') publications of frameworks, conceptual models, or theories (e.g. HBM). We intend to use the HBM as our 'best fit' framework. If this is not usable during data extraction, we will seek an alternative approach;

3. (a) extract data on study characteristics from the included studies and appraise the quality of studies; and b) generate the a priori framework from the modified HBM based on the thematic analysis of the identified publication(s). We will extract data using a data extraction form. We will appraise study quality using the Critical Appraisals Skills Programme (CASP) tool. We will generate an a priori framework from the analysis;

4. code evidence from the included studies against the a priori framework;

5. create new themes by performing secondary thematic analysis or thematic synthesis on any evidence that cannot be coded against the framework;

6. produce a new framework composed of a priori and new themes supported by the evidence; and
7. revisit evidence to explore relationships between themes or concepts, thus creating a model. 'Test' this synthesis and model by exploring the issues of dissonance and the impact of variables such as quality.

We will develop a 'Summary of qualitative findings' table from the synthesised findings once data extraction and analyses are completed.

\section{Assessment of the methodological limitations in included studies}

Two or more review authors (GD, CMCC, PW, JY) will independently assess methodological limitations for each study using the CASP Qualitative Checklist (www.casp-uk.net) to appraise the quality of the included studies and the GRADE-CERQual. For studies where information is unclear or missing from reports, we will attempt to contact the authors for further clarification. Any disagreements between review authors will be resolved through discussion or by involving a third review author (PB, JF). We will assess methodological limitations according to the following domains.

- Are the results valid?

- Is a qualitative methodology appropriate?

- Was the research design appropriate to address the aims of the research?

- Was the recruitment strategy appropriate to the aims of the research?

- Were the data collected in a way that addressed the research issue?

- Has the relationship between researcher and participants been adequately considered?

- Have ethical issues been taken into consideration?

- Was the data analysis sufficiently rigorous?

- Is there a clear statement of findings?

- How valuable is the research?

We will report our assessment of methodological limitations for each study in the 'Characteristics of included studies' tables. A further assessment of methodological limitations of the body of data supporting each review finding will also be reported (MuntheKaas 2018).

\section{Assessment of heterogeneity}

A QES can be a valuable way of investigating the reasons why an intervention is effective (or not). Sensitivity analyses in the linked effectiveness reviews looked at intervention type and dose. We will also consider the variability in theory of change, outcomes, study designs, populations, interventions, and settings based on the available evidence. We will address clinical and methodological heterogeneity by including explicit and detailed methods for the identification, selection, and rating of the quality of individual studies and overall evidence. The 'best fit' framework analysis approach is more likely to make heterogeneity between studies and issues of quality appraisal more transparent (Barnett-Page 2009).

\section{Assessment of confidence in the synthesis findings}

We will use the CERQual (Confidence in the Evidence from Reviews of Qualitative research) approach to assess our confidence in the review findings (Colvin 2013; Glenton 2013; Lewin 2018; Munthe-Kaas 2018; Noyes 2018). This approach, building on the 
GRADE approach and the Cochrane tool for assessing risk of bias (GRADE Working Group 2004; Higgins 2017), is becoming the standard to assess confidence in the findings from qualitative evidence syntheses (Ames 2017; Bohren 2017; Colvin 2013; MunabiBabigumira 2017). Four review authors (GD, CMcC, JY, PW) will independently assess the included studies. Any disagreements will be discussed amongst review authors and an additional review author (PB, JF) consulted if necessary. The CERQual approach assesses the following four concepts (Lewin 2018).

1. Methodological limitations of included studies: the extent to which there are concerns about the design or conduct of the primary studies that contributed evidence to an individual review finding. Confidence in a finding may be lowered by substantial methodological limitations.

2. Coherence of the review finding: an assessment of how clear and cogent the fit is between the data from the primary studies and the review finding that synthesises the data. 'Cogent' refers to a well-supported or compelling fit. Variations in data across the included studies without convincing and cogent explanations may lower the confidence in a review finding.

3. Adequacy of the data contributing to a review finding: an overall determination of the degree of richness and quantity of data supporting a review finding. Confidence in a finding may be lowered if a finding is supported by results from only one or a few of the included studies, or when the data supporting a finding are very thin.

4. Relevance of the included studies to the review question: the extent to which the body of evidence from the primary studies supporting a review finding is applicable to the context (perspective or population, phenomenon of interest, setting) specified in the review question. Confidence in a finding may be lowered when contextual issues in a primary study used to support a review finding are different to the context of the review question.

After assessing each of the four components, we will make a judgement about the overall confidence in the evidence supporting the review finding. We will judge confidence as high, moderate, low, or very low. The final assessment will be based on consensus amongst the review authors. All findings start as high confidence and will be graded down if there are important concerns regarding any of the CERQual components.

\section{'Summary of qualitative findings' table}

We will present the findings in a 'Summary of qualitative findings' table, which will include an assessment of confidence in the evidence, as well as an explanation of this assessment, based on the GRADE-CERQual approach (Lewin 2018).

\section{Linking the synthesised qualitative findings to a Cochrane Intervention review}

We will use the findings from the qualitative synthesis and combine these with findings from the two effectiveness reviews using a synthesis matrix outlining the barriers, facilitators, and implied recommendations against the actual interventions that have been implemented and evaluated, as described by Thomas and colleagues (Thomas 2004). We will draw on the original interventions in the included trials to see if any of them match recommendations emerging from the qualitative synthesis including the following.

- Which interventions match recommendations derived from views and experiences of service users, carers, service providers, or health professionals?

- Which recommendations have yet to be tried in soundly evaluated interventions?

- Do those interventions that match recommendations show bigger effect sizes or explain heterogeneity?

This information will be used to assess whether there is goodquality effectiveness evidence from trials and to identify gaps in the evidence. The interventions that have not been evaluated well but are identified as building on a potential facilitator will be recommended for more rigorous evaluation.

\section{ACK N O WLEDGEMENTS}

This review will inform research funded by the Disability Research on Independent Living and Learning (DRILL), which will involve the development of a co-produced physical activity intervention for people with lived experience of severe and enduring mental illness. $\mathrm{CMCC}$ was funded for 0.5 days per week over a three-month period to develop this protocol.

We thank the Cochrane Qualitative \& Implementation Methods Group for providing guidance during protocol development; and the editorial team of the Cochrane Common Mental Disorders (CCMD) Group including Sarah Dawson (Information Specialist) who helped develop the search strategies, Jessica Hendon and Sarah Hetrick.

The authors and the CCMD Editorial Team, are grateful to the peer reviewers for their time and comments including: Alan Bailey, Karen Morley, and Jane Noyes. They would also like to thank copy editor, Lisa Winer.

Cochrane Group funding acknowledgement: The National Institute for Health Research (NIHR) is the largest single funder of the Cochrane Common Mental Disorders Group.

Disclaimer: The views and opinions expressed herein are those of the authors and do not necessarily reflect those of the NIHR, National Health Service (NHS), or the Department of Health and Social Care. 


\section{RE F E R E N C E S}

\section{Additional references}

\section{Abu-Omar 2004}

Abu-Omar K, Rütten A, Lehtinen V. Mental health and physical activity in the European Union. Soz Praventivmed 2004;49:301-9.

\section{Ames 2017}

Ames HMR, Glenton C, Lewin S. Parents' and informal caregivers' views and experiences of communication about routine childhood vaccination: a synthesis of qualitative evidence. Cochrane Database of Systematic Reviews 2017, Issue 2. [DOI: 10.1002/14651858.CD011787.pub2]

\section{Andrews 1998}

Andrews G, Sanderson K, Beard J. Burden of disease: methods of calculating disability from mental disorder. British Journal of Psychiatry 1998;173:123-31.

\section{APA 2013}

American Psychiatric Association. Diagnostic and Statistical Manual of Mental Disorders. 5th Edition. Washington, DC: American Psychiatric Association, 2013.

\section{Argent 2018}

Argent R, Daly A, Caulfield B. Patient involvement with homebased exercise programs: can connected health interventions influence adherence?. JMIR Mhealth Uhealth 2018;6(3):e47. [DOI: 10.2196/mhealth.8518; 5856927; PUBMED: 29496655]

\section{Ashdown-Franks 2019}

Ashdown-Franks G, Firth J, Carney R, Carvalho AF, Hallgren M, Koyanagi $A$, et al. Exercise as medicine for mental and substance use disorders: a meta-review of the benefits for neuropsychiatric and cognitive outcomes. Sports Medicine Epub ahead of print:1-20. [DOI: 10.1007/s40279-019-01187-6]

\section{Asmundson 2013}

Asmundson GJ, Fetzner MG, DeBoer LB, Powers MB, Otto MW, Smits JA. Let's get physical: a contemporary review of the anxiolytic effects of exercise for anxiety and its disorders. Depression \& Anxiety 2013;30(4):362-73. [DOI: 10.1002/da.22043; PUBMED: 23300122]

\section{Azevedo Da Silva 2012}

Azevedo Da Silva M, Singh-Manoux A, Brunner EJ, Kaffashian S, Shipley MJ, Kivimäki M, et al. Bidirectional association between physical activity and symptoms of anxiety and depression: the Whitehall II study. European Journal of Epidemiology 2012;27(7):537-46. [DOI: 10.1007/s10654-012-9692-8]

\section{Bailey 2018}

Bailey AP, Hetrick SE, Rosenbaum S, Purcell R, Parker AG. Treating depression with physical activity in adolescents and young adults: a systematic review and meta-analysis of randomised controlled trials. Psychological Medicine 2018;48(7):1068-83. [DOI: 10.1017/S0033291717002653]

\section{Bandelow 2009}

Bandelow B, Michaelis S. Epidemiology of anxiety disorders in the 21st century. Dialogues in Clinical Neuroscience 2009;17(3):328-35. [PMC4610617; PUBMED: 26487813]

\section{Barnett-Page 2009}

Barnett-Page E, Thomas J. Methods for the synthesis of qualitative research: a critical review. BMC Medical Research Methodology 2009;9(1):59. [DOI: 10.1186/1471-2288-9-59]

\section{Bartels 2018}

Bartels SJ, Aschbrenner KA, Pratt SI, Naslund JA, Scherer EA, Zubkoff $\mathrm{L}$, et al. Implementation of a lifestyle intervention for people with serious mental illness in state-funded mental health centers. Psychiatric Services 2018;69(6):664-70. [DOI: 10.1176/appi.ps.201700368; PUBMED: 29606077]

\section{Basso 2017}

Basso JC, Suzuki WA. The effects of acute exercise on mood, cognition, neurophysiology, and neurochemical pathways: a review. Brain Plasticity 2017;2(2):127-52. [DOI: 10.3233/ BPL-160040]

\section{Batelaan 2016}

Batelaan NM, Seldenrijk A, Bot M, van Balkom AJ, Penninx BW. Anxiety and new onset of cardiovascular disease: critical review and meta-analysis. British Journal of Psychiatry 2016;208(3):223-31. [DOI: 10.1192/bjp.bp.114.156554; PUBMED: 26932485]

\section{Beck 2009}

Beck AT, Alford BA. Depression: Causes and Treatment. 2nd Edition. Philadelphia: University of Pennsylvania Press, 2009.

\section{Bivanco-Lima 2007}

Bivanco-Lima D, de Souza Santos I, Vannucchi AM, de Alemida Ribeiro MC. Cardiovascular risk in individuals with depression [Risco cardiovascular em indivíduos com depressão]. Revista da Associação Médica Brasileira 2013;59(3):298-304. [DOI: 10.1016/ j.ramb.2012.12.006]

\section{Blumenthal 2007}

Blumenthal JA, Babyak MA, Doraiswamy PM, Watkins L, Hoffman BM, Barbour KA, et al. Exercise and pharmacotherapy in the treatment of major depressive disorder. Psychosomatic Medicine 2007;69(7):587-96. [DOI: 10.1097/ PSY.0b013e318148c19a; PMC2702700; PUBMED: 17846259]

\section{Bohren 2017}

Bohren MA, Hofmeyr GJ, Sakala C, Fukuzawa RK, Cuthbert A. Continuous support for women during childbirth. Cochrane Database of Systematic Reviews 2017, Issue 7. [DOI: 10.1002/14651858.CD003766.pub6]

\section{Booth 2013}

Booth A, Harris J, Croot E, Springett J, Campbell F, Wilkins E. Towards a methodology for cluster searching to provide conceptual and contextual "richness" for systematic reviews 
of complex interventions: case study (CLUSTER). BMC Medical Research Methodology 2013;13:118.

\section{Booth 2015}

Booth A, Carroll C. How to build up the actionable knowledge base: the role of the 'best fit' framework synthesis for studies of improvement in healthcare. BMJ Quality \& Safety 2015;24(11):700-8. [DOI: 10.1136/bmjqs-2014-003642]

\section{Booth 2016}

Booth A, Noyes J, Flemming K, Gerardus A, Wahlster P, Van Der Wilt GJ, et al. Guidance on choosing qualitative evidence synthesis methods for use in health technology assessments of complex interventions. Available from: http://www.integratehta.eu/downloads/ 2016.

\section{Breedvelt 2019}

Breedvelt J, Amanvermez Y, Harrer M, Karyotaki E, Gilbody S, Bockting $C$, et al. The effects of meditation, yoga, and mindfulness on depression, anxiety, and stress in tertiary education students: a meta-analysis. Frontiers in Psychiatry 2019;10(193):1-15. [DOI: 10.3389/fpsyt.2019.00193]

\section{British Heart Foundation 2017}

British Heart Foundation. Physical activity and sedentary behaviour report 2017. bhf.org.uk/informationsupport/ publications/statistics/physical-inactivity-report-2017.

\section{Buckworth 2002}

Buckworth J, Dishman RK. Exercise psychology. Champaign, IL: Human Kinetics, 2002.

\section{Bélanger 2011}

Bélanger M, Casey M, Cormier M. Maintenance and decline of physical activity during adolescence: insights from a qualitative study. International Journal of Behavioral Nutrition and Physical Activity 2011;8:117. [DOI: 10.1186/1479-5868-8-117]

\section{Carek 2011}

Carek PJ, Laibstain SE, Carek SM. Exercise for the treatment of depression and anxiety. Journal of Psychiatry in Medicine 2011;41(1):15-28. [DOI: 10.2190/PM.41.1.c]

\section{Carless 2008}

Carless D, Douglas K. The contribution of exercise and sport to mental health promotion in serious mental illness: an interpretive project. International Journal of Mental Health Promotion 2008;10(4):5-12. [DOI: $10.1080 / 14623730.2008 .9721771]$

\section{Carneiro 2015}

Carneiro LS, Fonseca AM, Vieira-Coelho MA, Mota MP, Vasconcelos-Raposo J. Effects of structured exercise and pharmacotherapy vs. pharmacotherapy for adults with depressive symptoms: a randomized clinical trial. Journal of Psychiatric Research 2015;71:48-55. [DOI: 10.1016/ j.jpsychires.2015.09.007; PUBMED: 26522871]
Health Communication 2010;25(8):661-9. [DOI:

$10.1080 / 10410236.2010 .521906]$

\section{Carroll 2011}

Carroll C, Booth A, Cooper K. A worked example of "best fit" framework synthesis: a systematic review of views concerning the taking of some potential chemopreventive agents. BMC Medical Research Methodology 2011;11(1):29. [DOI: 10.1186/1471-2288-11-29]

\section{Carroll 2013}

Carroll C, Booth A, Leaviss J, Rick J. "Best fit" framework synthesis: refining the method. BMC Medical Research Methodology 2013;13(1):37. [DOI: 10.1186/1471-2288-13-37]

\section{Carta 2008}

Carta MG, Hardoy MC, Pilu A, Sorba M, Floris AL, Mannu FA, et al. Improving physical quality of life with group physical activity in the adjunctive treatment of major depressive disorder. Clinical Practice \& Epidemiology in Mental Health 2008;4(1):1-6. [DOI: 10.1186/1745-0179-4-1; PMC2266746; PUBMED: 18221549]

\section{Caspersen 1985}

Caspersen CJ, Powell KE, Christenson GM. Physical activity, exercise, and physical fitness: definitions and distinctions for health-related research. Public Health Reports 1985;100(2):123-31. [PMC1424733; PUBMED: 3920711]

\section{Champion 2008}

Champion VL, Skinner CS. The Health Belief Model. In: Glanz K, Rimer BK, Viswanath K editor(s). Health Behavior and Health Education. Theory, Research, and Practice. 4th Edition. San Francisco: Jossey-Bass, 2008:45-62.

\section{Cohen 2015}

Cohen BE, Edmondson D, Kronish IM. State of the art review: depression, stress, anxiety and cardiovascular disease. American Journal of Hypertension 2015;28(11):1295-302.

\section{Cole 2010}

Cole F. Physical activity for its mental health benefits: conceptualising participation within the Model of Human Occupation. British Journal of Occupational Therapy 2010;73(12):607-15. [DOI: 10.4276/030802210X12918167234280]

\section{Coleman 2008}

Coleman L, Cox L, Roker D. Girls and young women's participation in physical activity: psychological and social influences. Health Education Research 2008;23(4):633-47. [DOI: 10.1093/her/cym040]

\section{Colvin 2013}

Colvin CJ, Heer J, Winterton L, Mellenkamp M, Glenton C, Noyes $\mathrm{J}$, et al. A systematic review of qualitative evidence on barriers and facilitators to the implementation of task-shifting in midwifery services. Midwifery 2013;29(10):1211-21. [DOI: 10.1016/j.midw.2013.05.001]

\section{Carpenter 2010}

Carpenter CJ. A meta-analysis of the effectiveness of health belief model variables in predicting behavior. 


\section{Cooney 2014}

Cooney G, Dwan K, Mead G. Exercise for depression. JAMA 2014;311(23):2432-3. [DOI: 10.1001/jama.2014.4930; PUBMED: 24938566]

\section{Cooper 2015}

Cooper AA, Conklin LR. Dropout from individual psychotherapy for major depression: a meta-analysis of randomized clinical trials. Clinical Psychology Review 2015;40:57-65. [DOI: 10.1016/ j.cpr.2015.05.001; PUBMED: 26067572]

\section{Crone 2008}

Crone D, Guy H. "I know it is only exercise, but to me it is something that keeps me going": a qualitative approach to understanding mental health service users' experiences of sports therapy. International Journal of Mental Health Nursing 2008;17(3):197-207. [DOI: 10.1111/j.1447-0349.2008.00529.x; PUBMED: 18460081]

\section{Cross-Disorder Group 2013}

Cross-Disorder Group of the Psychiatric Genomics Consortium. Identification of the risk loci with shared effects on five major psychiatric disorders: a genome-wide analysis. Lancet 2013;381(9875):1317-9. [DOI: 10.1016/S0140-6736(12)62129-1]

\section{de Bruin 2007}

de Bruin El, Ferdinand RF, Meester S, de Nijs PF, Verheij F. High rates of psychiatric co-morbidity in PDD-NOS. Journal of Autism and Developmental Disorders 2007;37(5):877-86. [DOI: 10.1007/ s10803-006-0215-x; PUBMED: 17031447]

\section{de Hert 2013}

de Hert M, Correll CU, Bobes J, Cetkovich-Bakmas M, Cohen D, Asai I, et al. Physical illness in patients with severe mental disorders. I. Prevalence, impact of medications and disparities in health care. Work Psychiatry 2013;10(1):52-77. [DOI: 10.1002/ j.2051-5545.2011.tb00014.x]

\section{de Wit 2010}

de Wit LM, Fokkema M, van Straten A, Lamers F, Cuijpers P, Penninx B. Depressive and anxiety disorders and the association with obesity, physical, and social activities. Depression and Anxiety 2010;27(11):1057-65. [DOI: 10.1002/ da.20738]

\section{Ding 2016}

Ding D, Lawson KD, Kolbe-Alexander TL, Finkelstein EA, Katzmarzyk PT, van Mechelen W, et al. Lancet Physical Activity Series 2 Executive Committee. The economic burden of physical inactivity: a global analysis of major noncommunicable diseases. Lancet 2016;388:1311-24. [DOI: 10.1016/S0140-6736(16)30383-X]

\section{Dishman 1985}

Dishman RK, Sallis JF, Orenstein DR. The determinants of physical activity and exercise. Public Health Reports 1985;100(2):158-71. [MEDLINE: 3920714; PMC1424729]

\section{Dishman 2009}

Dishman R, O'Connor PJ. Lessons in exercise neurobiology: the case of endorphins. Mental Health \& Physical Activity 2009;2(1):4-9. [DOI: 10.1016/j.mhpa.2009.01.002]

\section{Dumith 2011}

Dumith SC, Gigante DP, Domingues MR, Kohl HW 3rd. Physical activity change during adolescence: a systematic review and a pooled analysis. International Journal of Epidemiology 2011;40(3):685-98. [DOI: 10.1093/ije/dyq272]

\section{Ehrlich 2015}

Ehrlich C, Kendall E, Frey N, Denton M, Kisely S. Consensus building to improve the physical health of people with severe mental illness: a qualitative outcome mapping study. $B M C$ Health Services Research 2015;15(83):1-9. [DOI: 10.1186/ s12913-015-0744-0; PMC4351836; PUBMED: 25879760]

\section{Elliott 2016}

Elliott I. Poverty and mental health. www.mentalhealth.org.uk/ sites/default/files/Poverty\%20and\%20Mental\%20Health.pdf (accessed 24 January 2019).

\section{EndNote 2019 [Computer program]}

Clarivate Analytics. EndNote. Philadelphia: Clarivate Analytics, 2019.

\section{Fagiolini 2009}

Fagiolini A, Goracci A. The effects of undertreated chronic mental illness in patients with severe mental disorders. Journal of Clinical Psychiatry 2009;70(Suppl 3):22-9. [DOI: 10.4088/ JCP.7075su1c.04]

\section{Fava 2000}

Fava M, Kendler KS. Major depressive disorder. Neuron 2000;28:335-41. [DOI: 10.1016/S0896-6273(00)00112-4]

\section{Firth 2016a}

Firth J, Carney R, Jerome L, Elliott R, French P, Yung AR. The effects and determinants of exercise participation in first-episode psychosis: a qualitative study. BMC Psychiatry 2016;16(36):1-9. [DOI: 10.1186/s12888-016-0751-7; PMC4761413; PUBMED: 26896958]

\section{Firth 2016b}

Firth J, Rosenbaum S, Stubbs B, Gorczynski P, Yung AR, Vancampfort $\mathrm{D}$. Motivating factors and barriers towards exercise in severe mental illness: a systematic review and meta-analysis. Psychological Medicine 2016;46(14):1-13. [DOI: 10.1017/ S0033291716001732]

\section{Garber 2011}

Garber CE, Blissmer B, Deschenes MR, Franklin BA, Lamonte MJ, Lee IM, et al. American College of Sports Medicine. American College of Sports Medicine position stand. Quantity and quality of exercise for developing and maintaining cardiorespiratory, musculoskeletal, and neuromotor fitness in apparently healthy adults: guidance for prescribing exercise. Medicine \& Science in Sports \& Exercise 2011;43(7):1334-59. [DOI: 10.1249/ MSS.0b013e318213fefb; PUBMED: 21694556] 


\section{Gerber 2014}

Gerber M, Brand S, Hermann C, Colledge F, HolsboerTrachsler E, Puhse U, et al. Increased objectively assessed vigorous-intensity exercise is associated with reduced stress, increased mental health and good objective and subjective sleep in young adults. Physiology \& Behavior 2014;135:17-24. [DOI: 10.1016/j.physben.2014.05.047; PUBMED: 24905432]

\section{Gilbody 2019}

Gilbody S, Peckham E, Bailey D, Arundel C, Heron P, Crosland S, et al. Smoking cessation for people with severe mental illness (SCIMITAR+): a pragmatic randomised controlled trial. The Lancet Psychiatry 2019;6(5):379-90. [DOI: 10.1016/ S2215-0366(19)30047-1]

\section{Glanz 2010}

Glanz K, Bishop DB. The role of behavioral science theory in development and implementation of public health interventions. Annual Review of Public Health 2010;31:399-418. [DOI: 10.1146/annurev.publhealth.012809.103604]

\section{Glenton 2013}

Glenton C, Colvin C, Carlsen B, Swartz A, Lewin S, Noyes J, et al. Barriers and facilitators to the implementation of lay health worker programmes to improve access to maternal and child health: qualitative evidence synthesis. Cochrane Database of Systematic Reviews 2013, Issue 10. [DOI: 10.1002/14651858.CD010414.pub2]

\section{Glowacki 2017}

Glowacki K, Duncan MJ, Gainforth H, Faulkner G. Barriers and facilitators to physical activity and exercise among adults with depression: a scoping review. Mental Health \& Physical Activity 2017;13:108-19. [DOI: 10.1016/j.mhpa.2017.10.001]

\section{Goodwin 2003}

Goodwin RD. Association between physical activity and mental disorders among adults in the United States. Prev Med 2003;36:698-703.

\section{GRADE Working Group 2004}

GRADE Working Group. Grading quality of evidence and strength of recommendations. BMJ 2004;328:1490-4. [DOI: 10.1136/bmj.328.7454.1490]

\section{Greer 2016}

Greer TL, Trombello JM, Rethorst CD, Carmody TJ, Jha MK, Liao A, et al. Improvements in psychosocial functioning and health-related quality of life following exercise augmentation in patients with treatment response but nonremitted major depressive disorder: results from the TREAD study. Depression \& Anxiety 2016;33(9):870-81. [DOI: 10.1002/da.22521; PMC5662022 ; PUBMED: 27164293]

\section{Gristwood 2011}

Gristwood J. Applying the Health Belief Model to physical activity engagement among older adults. Illuminare: $a$ Student Journal in Recreation, Parks, and Leisure Studies 2011;9(1):59-71.

\section{Hallgren 2016}

Hallgren M, Helgadóttir B, Herring MP, Zeebari Z, Lindefors N, Kaldo V, et al. Exercise and internet-based cognitive-behavioural therapy for depression: multicentre randomised controlled trial with 12-month follow-up. British Journal of Psychiatry 2016;209(5):414-20. [DOI: 10.1192/bjp.bp.115.177576]

\section{Harris 2008}

Harris JL, Booth A, Cargo M, Hannes K, Harden A, Flemming K, et al. Cochrane Qualitative and Implementation Methods Group guidance series - paper 2: methods for question formulation, searching, and protocol development for qualitative evidence synthesis. Journal of Clinical Epidemiology 2018;97:39-48. [DOI: 10.1016/j.jclinepi.2017.10.023; PUBMED: 29248725]

\section{Herring 2011}

Herring MP, Jacob ML, Suveg C, Dishman RK, O'Connor PJ. Feasibility of exercise training for the short-term treatment of generalized anxiety disorder: a randomized controlled trial. Psychotherapy \& Psychosomatics 2011;81(1):21-8. [DOI: 10.1159/000327898; PUBMED: 22116310]

\section{Hettema 2001}

Hettema JM, Neale MC, Kendler KS. A review and meta-analysis of the genetic epidemiology of anxiety disorders. American Journal of Psychiatry 2001;158(10):1568-78. [DOI: 10.1176/ appi.ajp.158.10.1568]

\section{Higgins 2017}

Higgins JP, Altman DG, Sterne JA on behalf of the Cochrane Statistical Methods Group and the Cochrane Bias Methods Group. Chapter 8: Assessing risk of bias in included studies. In: Higgins JP, Churchill R, Chandler J, Cumpston MS editor(s), Cochrane Handbook for Systematic Reviews of Interventions version 5.2.0 (updated June 2017), Cochrane, 2017. Available from www.training.cochrane.org/handbook.

\section{Hoare 2016}

Hoare E, Milton K, Foster C, Allender S. The associations between sedentary behaviour and mental health among adolescents: a systematic review. International Journal of Behavioral Nutrition and Physical Activity 2016;13(108):1-22. [DOI: 10.1186/s12966-016-0432-4]

\section{Hochbaum 1958}

Hochbaum G. Public participation in medical screening programs: a sociopsychological study. Public participation in medical screening programs: a sociopsychological study. Public Health Service Publication no. 572. Washington: United States. Public Health Service. Division of Special Health Services, 1958.

\section{Hodgson 2011}

Hodgson MH, McCulloch HP, Fox KR. The experiences of people with severe and enduring mental illness engaged in a physical activity programme integrated into the mental health service. Mental Health and Physical Activity 2011;4(1):23-9.

\section{Hoffman 2014}

Hoffmann TC, Glasziou PP, Boutron I, Milne R, Perera R, Moher D, et al. Better reporting of interventions: template for 
intervention description and replication (TIDieR) checklist and guide. 2014 2014;348:g1687. [DOI: 10.1136/bmj.g1687]

\section{Hosseini 2017}

Hosseini H, Moradi R, Kazemi A, Sadat Shadshahani M. Determinants of physical activity in middle-aged women in Isfahan using the health belief model. Journal of Education and Health Promotion 2017;6:26. [DOI: 10.4103/jehp.jehp_68_15]

\section{Janz 1984}

Janz NK, Becker MH. The Health Belief Model: a decade later. Health Education Quarterly 1984;11(1):1-47. [DOI: $10.1177 / 109019818401100101]$

\section{Jayakody 2014}

Jayakody K, Gunadasa S, Hosker C. Exercise for anxiety disorders: systematic review. British Journal of Sports Medicine 2014;48(3):187-96. [DOI: 10.1136/bjsports-2012-091287]

\section{Johnston 2008}

Johnston M, Dixon D. Current issues and new directions in psychology and health: what happened to behaviour in the decade of behaviour?. Psychology and Health 2008;23(5):509-13. [DOI: 10.1080/08870440701816728]

\section{Jones 2005}

Jones F, Harris P, Waller H, Coggins A. Adherence to an exercise prescription scheme: the role of expectations, selfefficacy, stage of change and psychological well-being. British Journal of Health Psychology 2005;10(3):359-78. [10.1348/135910704X24798; PUBMED: 16238853]

\section{Jones 2014}

Jones CJ, Smith H, Llewellyn C. Evaluating the effectiveness of health belief model interventions in improving adherence: a systematic review. Health Psychology Review 2014;8(3):253-69. [DOI: 10.1080/17437199.2013.802623]

\section{Josefsson 2014}

Josefsson T, Lindwall M, Archer T. Physical exercise intervention in depressive disorders: meta-analysis and systematic review. Scandinavian Journal of Medicine \& Science in Sports 2014:24(2):259-72. [DOI: 10.1111/sms.12050]

\section{Karimi-Shahanjarini 2019}

Karimi-Shahanjarini A, Shakibazadeh E, Rashidian A, Hajimiri K, Glenton C, Noyes J, et al. Barriers and facilitators to the implementation of doctor-nurse substitution strategies in primary care: a qualitative evidence synthesis. Cochrane Database of Systematic Reviews 2019, Issue 4. [DOI: 10.1002/14651858.CD010412.pub2]

\section{Kasser 2012}

Kasser SL, Kosma M. Health beliefs and physical activity behavior in adults with multiple sclerosis. Disability Health Journal 2012;5(4):261-8. [DOI: 10.1016/j.dhjo.2012.07.001]

\section{Kerns 2015}

Kerns CM, Kendall PC, Zickgraf H, Franklin ME, Miller J, Herrington J. Not to be overshadowed or overlooked: functional impairments associated with comorbid anxiety disorders in youth with ASD. Behavior Therapy 2015;46(1):29-39. [DOI: 10.1016/j.beth.2014.03.005; PUBMED: 25526833]

\section{Kessler 1999}

Kessler RC, DuPont RL, Berglund P, Wittchen H-U. Impairment in pure and comorbid generalized anxiety disorder and major depression at 12 months in two national surveys. American Journal of Psychiatry 1999;156:1915-23. [DOI: 10.1176/ ajp.156.12.1915]

\section{Kessler 2009}

Kessler RC, Ruscio AM, Shear K, Wittchen HU. Epidemiology of anxiety disorders. In: Stein M, Steckler T editor(s). Behavioral Neurobiology of Anxiety and Its Treatment. Vol. 2, Berlin: Springer, 2009.

\section{Kisely 2007}

Kisely S, Smith M, Lawrence D, Cox M, Campbell LA, Maaten S. Inequitable access for mentally ill patients to some medically necessary procedures. Canadian Medical Association Journal 2007;176(6):779-84. [PMC1808525]

\section{Krogh 2011}

Krogh J, Nordentoft M, Sterne J, Lawlor DA. The effect of exercise in clinical depressed adults: systematic review and meta-analysis of randomized controlled trials. Journal of Clinical Psychiatry 2011;72(4):529-38.

\section{Kupfer 2015}

Kupfer DJ. Anxiety and DSM-5. Dialogues in Clinical Neuroscience 2015;17(3):245-6. [PMC4610609; PUBMED: 26487805]

\section{Kvam 2016}

Kvam S, Kleppe CL, Nordhus IH, Hovland A. Exercise as a treatment for depression: a meta-analysis. Journal of Affective Disorders 2016;202:67-86. [DOI: 10.1016/j.jad.2016.03.063; PUBMED: 27253219]

\section{Kyu 2016}

Kyu HH, Backman VF, Alexander LT, Mumford JE, Afshin A, Estep K, et al. Physical activity and risk of breast cancer, colon cancer, diabetes, ischemic heart disease, and ischemic stroke events: systematic review and dose-response meta analysis for the Global Burden of Disease Study 2013. BMJ 2016;354:i3857. [DOI: 10.1136/bmj.i3857]

\section{Lader 2015}

Lader M. Generalized anxiety disorder. In: Stolerman I, Price L editor(s). Encyclopedia of Psychopharmacology. Berlin: Springer, 2015.

\section{Larun 2006}

Larun L, Nordheim LV, Ekeland E, Hagen KB, Heian F. Exercise in prevention and treatment of anxiety and depression among children and young people. Cochrane Database of Systematic Reviews 2006, Issue 3. [DOI: 10.1002/14651858.CD004691.pub2]

\section{Lawrence 2010}

Lawrence D, Kisely S. Review: inequalities in healthcare provision for people with severe mental illness. 
Journal of Psychopharmacology 2010;24(4):61-8. [DOI: 10.1177/1359786810382058; PUBMED: 20923921]

\section{Lee 2012}

Lee IM, Shiroma EJ, Lobelo F, Puska P, Blair SN, Katzmarzyk PT, Lancet Physical Activity Series Working Group. Effect of physical inactivity on major non-communicable diseases worldwide: an analysis of burden of disease and life expectancy. Lancet 2012;380(9838):219-29. [DOI: 10.1016/S0140-6736(12)61031-9; PMC3645500 ; PUBMED: 22818936]

\section{Lewin 2018}

Lewin S, Booth A, Glenton C, Munthe-Kaas H, Rashidian A, Wainwright M, et al. Applying Grade-CERQual to qualitative evidence synthesis findings: introduction to the series. Implementation Sciences 2018;13(Suppl 1):2. [DOI: 10.1186/ s13012-017-0688-3]

\section{Lubans 2016}

Lubans D, Richards J, Hillman CH, Faulkner G, Beauchamp MR, Nilsson M, et al. Physical activity for cognitive and mental health in youth: a systematic review of mechanisms. Pediatrics 2016;138(3):e20161642. [DOI: 10.1542/peds.2016-1642; PUBMED: 27542849]

\section{Mandolesi 2018}

Mandolesi L, Polverino A, Montuori S, Foti F, Ferraioli G, Sorrentino $\mathrm{P}$, et al. Effects of physical exercise on cognitive functioning and wellbeing: biological and psychological benefits. Frontiers in Psychology 2018;9(509):1-11. [DOI: 10.3389/fpsyg.2018.00509; PMC5934999; PUBMED: 29755380]

\section{Martins 2015}

Martins J, Marques A, Sarmento H, Carreiro da Costa F. Adolescents' perspectives on the barriers and facilitators of physical activity: a systematic review of qualitative studies. Health Education Research 2015;30(5):745-55. [DOI: 10.1093/ her/cyv042]

\section{Martinsen 1989}

Martinsen EW, Strand J, Paulsson G, Kaggestad J. Physical fitness level in patients with anxiety and depressive disorders. Int J Sport Med 1989;10:58-62.

\section{Martinsen 2008}

Martinsen EW. Physical activity in the prevention and treatment of anxiety and depression. Nordic Journal of Psychiatry 2008;62(Suppl 47):25-9. [DOI: 10.1080/08039480802315640; PUBMED: 18752115]

\section{Martiny 2012}

Martiny K, Refsgaard E, Lund V, Lunde M, Sørensen L, Thougaard B, et al. A 9-week randomized trial comparing chronotherapeutic intervention (wake and light therapy) to exercise in major depressive disorder patients treated with duloxetine. Journal of Clinical Psychiatry 2012;73(9):1234-42. [DOI: 10.4088/JCP.11m07625; PUBMED: 23059149]

\section{Maser 1990}

Maser JD, Cloninger CR. Comorbidity of Mood and Anxiety Disorders. Washington, DC: American Psychiatric Press, 1990.

\section{McCartan (in press)}

McCartan C, Yap J, Firth J, Stubbs B, Tully M, Best P, et al. Factors that influence participation in physical activity for people with bipolar disorder: a synthesis of qualitative evidence. Cochrane Database of Systematic Reviews (in press).

\section{Meekums 2015}

Meekums B, Karkou V, Nelson A. Dance movement therapy for depression. Cochrane Database of Systematic Reviews 2015, Issue 2. [DOI: 10.1002/14651858.CD009895.pub2; PUBMED: 25695871]

\section{Mitchell 2009}

Mitchell AJ, Malone D, Doebbeling CC. Quality of medical care for people with and without comorbid mental illness and substance misuse: systematic review of comparative studies. British Journal of Psychiatry 2009;194(6):491-9. [DOI: 10.1192/ bjp.bp.107.045732]

\section{Motl 2004}

Motl RW, Birnbaum AS, Kubik MY, Dishman RK. Naturally occurring changes in physical activity are inversely related to depressive symptoms during early adolescence. Psychosom Med 2004;66:336-42.

\section{Mullainathan 2013}

Mullainathan S, Shafir E. Scarcity: The True Cost of Not Having Enough. London: Penguin, 2014.

\section{Munabi-Babigumira 2017}

Munabi-Babigumira S, Glenton C, Lewin S, Fretheim A, Nabudere $\mathrm{H}$. Factors that influence the provision of intrapartum and postnatal care by skilled birth attendants in low- and middle-income countries: a qualitative evidence synthesis. Cochrane Database of Systematic Reviews 2017, Issue 11. [DOI: 10.1002/14651858.CD011558]

\section{Munthe-Kaas 2018}

Munthe-Kaas H, Bohren MA, Glenton C, Lewin S, Noyes J, Tuncalp O, et al. Applying Grade-CERQual to qualitative evidence synthesis findings - paper 3: how to assess methodological limitations. Implementation Science 2018;13(Suppl 1):9. [DOI: 10.1186/s13012-017-0690-9]

\section{Naci 2013}

$\mathrm{Naci} \mathrm{H}$, loannidis JP. Comparative effectiveness of exercise and drug interventions on mortality outcomes: meta epidemiological study. BMJ 2013;347:f5577. [DOI: 10.1136/ bmj.f5577]

\section{Naylor 2016}

Naylor C, Das P, Ross S, Honeyman M, Thompson J, Gilburt H. Bringing Together Physical and Mental Health: a New Frontier for Integrated Care. London: The Kings Fund, 2016.

\section{Nestler 2002}

Nestler EJ, Barrot M, DiLeone RJ, Eisch AJ, Gold SJ, Monteggia LM. Neurobiology of depression. Neuron 2002;34(1):13-25. [DOI: 10.1016/S0896-6273(02)00653-0] 


\section{NHS 2018}

NHS. Every mind matters. www.nhs.uk/oneyou/everymindmatters/ (accessed 5 December 2018).

\section{NICE 2014}

National Institute for Health and Care Excellence (NICE). Physical activity: exercise referral schemes. Public health guideline [PH54]. www.nice.org.uk/guidance/ph54 (accessed 7 June 2019).

\section{NICE 2018}

National Institute for Health and Care Excellence (NICE). Depression in adults: recognition and management. Clinical guideline [CG90]. www.nice.org.uk/guidance/cg90 (accessed 7 June 2019).

\section{NICE 2019}

National Institute for Health and Care Excellence (NICE). Generalised anxiety disorder and panic disorder in adults: management. Clinical guideline [CG113]. www.nice.org.uk/ guidance/cg113 (accessed 30 December 2019)..

\section{Noyes 1998}

Noyes R Jr, Hoehn-Saric R. The Anxiety Disorders. Cambridge: Cambridge University Press, 1998.

\section{Noyes 2015}

Noyes J, Hendry M, Booth A, Lewin S, Glenton C, Garside R, et al. Guidance for Review Authors on Choice and Use of Theory in Complex Intervention Reviews. Version 1. London: Cochrane, 2015.

\section{Noyes 2016}

Noyes J, Hendry M, Lewin S, Glenton C, Chandler J, Rashidian A. Qualitative "trial-sibling" studies and "unrelated" qualitative studies contributed to complex intervention reviews. Journal of Clinical Epidemiology 2016;74:133-43. [DOI: 10.1016/ j.jclinepi.2016.01.009]

\section{Noyes 2018}

Noyes J, Booth A, Lewin S, Carlsen B, Glenton C, Colvin CJ, et al. Applying GRADE-CERQual to qualitative evidence synthesis findings - paper 6: how to assess relevance of the data. Implementation Science 2018;13(Suppl 1):4. [DOI: 10.1186/ s13012-017-0693-6]

\section{Olfson 1997}

Olfson M, Fireman B, Weissman MM, Leon AC, Sheehan DV, Kathol RG, et al. Mental disorders and disability among patients in a primary care group practice. American Journal of Psychiatry 1997;154(12):1734-40. [DOI: 10.1176/ajp.154.12.1734]

\section{Oman 2003}

Oman RF, Oman KK. A case-control study of psychosocial and aerobic exercise factors in women with symptoms of depression. Journal of Psychology: Interdisciplinary \& Applied 2003;137(4):338-50. [DOI: 10.1080/00223980309600618; PUBMED: 12943184]

\section{Orji 2012}

Orji R, Vassileva J, Mandryk R. Towards an effective health interventions design: an extension of the Health Belief Model. Online Journal of Public Health Informatics 2012;4(3):ojphi.v4i3.4321. [DOI: 10.5210/ojphi.v4i3.4321; PMC3615835; PUBMED: 23569653]

\section{Patton 2002}

Patton MQ. Qualitative Research and Evaluation Methods. 3rd Edition. Thousand Oaks, CA: Sage Publications, 2002.

\section{Peluso 2005}

Peluso MA, Andrade LH. Physical activity and mental health: the association between exercise and mood. Clinics 2005;60(1):61-70. [DOI: 10.1590/S1807-59322005000100012]

\section{Penedo 2005}

Penedo FJ, Dahn JR. Exercise and well-being: a review of mental and physical health benefits associated with physical activity. Current Opinion in Psychiatry 2005;18(2):189-93.

\section{Price 2018}

Price N, Williams T, Horton E, Liguori G, Mann S, Jimenez A. Effects of exercise referral schemes on physical activity levels. Medicine \& Sciences in Sports \& Exercise 2018;50(5S):48. [DOI: 10.1249/01.mss.0000535240.84785.24]

\section{Reddy 2010}

Reddy MS. Depression: the disorder and the burden. Indian Journal of Psychological Medicine 2010;32(1):1-2. [DOI: 10.4103/0253-7176.70510; PMC3137804; PUBMED: 21799550]

\section{Reed 2009}

Reed J, Buck S. The effect of regular aerobic exercise on positive-activated affect: a meta-analysis. Psychology of Sport \& Exercise 2009;10(6):581-94. [DOI: 10.1016/ j.psychsport.2009.05.009]

\section{Rethorst 2013}

Rethorst CD, Sunderajan P, Greer TL, Grannemann BD, Nakonezny PA, Carmody TJ, et al. Does exercise improve selfreported sleep quality in non-remitted major depressive disorder?. Psychological Medicine 2013;43(4):699-709. [DOI: 10.1017/S0033291712001675; PUBMED: 23171815]

\section{Roest 2012}

Roest AM, Zuidersma M, de Jonge P. Myocardial infarction and generalised anxiety disorder: 10-year follow up. British Journal of Psychiatry 2012;200(4):324-9. [DOI: 10.1192/ bjp.bp.111.103549; PUBMED: 22403086]

\section{Rosenstock 1960}

Rosenstock IM. What research in motivation suggests for public health. American Journal of Public Health 1960;50:295-302. [DOI: 10.2105/AJPH.50.3_Pt_1.295]

\section{Rosenstock 1974}

Rosenstock IM. Historical origins of the Health Belief Model. Health Education Monographs 1974;2:328-35. [DOI: 10.1177/109019817400200403] 


\section{Rubin 2000}

Rubin HC, Rapaport MH, Levine B, Gladsjo JK, Rabin A, Auerbach $\mathrm{M}$, et al. Quality of well being in panic disorder: the assessment of psychiatric and general disability. Journal of Affective Disorders 2000;57:217-21. [DOI: 10.1016/ S0165-0327(99)00030-0]

\section{Sadler 2017}

Sadler K, Vizard T, Ford T, Marcheselli F, Pearce N, Mandalia D, et al. Mental health of children and young people in England, 2017. digital.nhs.uk/data-and-information/publications/ statistical/mental-health-of-children-and-young-people-inengland/2017/2017.

\section{Sanders 1999}

Sanders AR, Detera-Wadleigh SD, Gershon ES. Molecular genetics of mood disorders. In: Charney DS, Nestler BS, Bunney BS editor(s). Neurobiology of Mental Illness. Oxford: Oxford University Press, 1999:299-316.

\section{Sartorius 1996}

Sartorius N, Ustün TB, Lecrubier Y, Wittchen H-U. Depression comorbid with anxiety: results from the WHO study on psychological disorders in primary health care. British Journal of Psychiatry 1996;168(S30):38-43. [PUBMED: 8864147]

\section{Schuch 2016}

Schuch FB, Dunn AL, Kanitz AC, Delevatti RS, Fleck MP. Moderators of response in exercise treatment for depression: a systematic review. Journal of Affective Disorders 2016;195:40-9. [DOI: 10.1016/j.jad.2016.01.014; PUBMED: 26854964]

\section{Schuch 2017}

Schuch F, Vancampfort D, Firth J, Rosenbaum S, Ward P, Reichert T, et al. Physical activity and sedentary behavior in people with major depressive disorder: a systematic review and meta-analysis. J Affect Disord 2017;210:139-50. [DOI: 10.1016/ j.jad.2016.10.050]

\section{Schuch 2018}

Schuch FB, Vancampfort D, Firth J, Rosenbaum S, Ward PB, Silva ES, et al. Physical activity and incident depression: a meta-analysis of prospective cohort studies. American Journal of Psychiatry 2018;175(7):631-48. [DOI: 10.1176/ appi.ajp.2018.17111194; PUBMED: 29690792]

\section{Searle 2012}

Searle A, Calnan M, Turner KM, Lawlor DA, Campbell J, Chalder M, et al. General practitioners' beliefs about physical activity for managing depression in primary care. Mental Health \& Physical Activity 2012;5(1):13-9. [DOI: 10.1016/ j.mhpa.2011.11.001]

\section{Searle 2014}

Searle A, Haase AM, Chalder M, Fox KR, Taylor AH, Lewis G, et al. Participants' experiences of facilitated physical activity for the management of depression in primary care. Journal of Health Psychology 2014;19(11):1430-42. [DOI: 10.1177/1359105313493648; PUBMED: 24021723]

\section{Shao 2018}

Shao C, Wang J, Liu J, Tian F, Li H. Effect of a Health Belief Model-based education program on patients' belief, physical activity, and serum uric acid: a randomized controlled trial. Patient Preference and Adherence 2018;12:1239-45. [DOI: 10.2147/PPA.S166523]

\section{Stanton 2014}

Stanton R, Reaburn P. Exercise and the treatment of depression: a review of the exercise program variables. Journal of Science and Medicine in Sport 2014;17(2):177-82. [DOI: 10.1016/ j.jsams.2013.03.010]

\section{Strine 2008}

Strine TW, Mokdad AH, Balluz LS, Gonzalez O, Crider R, Berry JT, et al. Depression and anxiety in the United States: findings from the 2006 behavioral risk factor surveillance system. Psychiatric Services 2008;59(12):1383-90. [DOI: 10.1176/appi.ps.59.12.1383; PUBMED: 19033164]

\section{Ströhle 2008}

Ströhle A. Physical activity, exercise, depression and anxiety disorders. Journal of Neural Transmission 2008;116:777-84. [DOI: 10.1007/s00702-008-0092-x]

\section{Stubbs 2016}

Stubbs B, Vancampfort D, Rosenbaum S, Ward PB, Richards J, Soundy $A$, et al. Dropout from exercise randomized controlled trials among people with depression: a meta-analysis and meta regression. Journal of Affective Disorders 2016;190:457-66. [DOI: 10.1016/j.jad.2015.10.019]

\section{Stubbs 2017}

Stubbs B, Koyanagi A, Hallgren M, Firth J, Richards J, Schuch F, et al. Physical activity and anxiety: a perspective from the World Health Survey. Journal of Affective Disorders 2017;208:545-52. [DOI: 10.1016/j.jad.2016.10.028; PUBMED: 27802893]

\section{Stubbs 2018}

Stubbs B, Vancampfort D, Hallgren M, Firth J, Veronese N, Solmi M, et al. EPA guidance on physical activity as a treatment for severe mental illness: a meta-review of the evidence and Position Statement from the European Psychiatric Association (EPA), supported by the International Organization of Physical Therapists in Mental Health (IOPTMH). European Psychiatry 2018;1(54):124-44. [DOI: 10.1016/j.eurpsy.2018.07.004]

\section{Sund 2004}

Sund AM, Larsson B, Wickstrøm L, Morken G. Does physical activity protect against depressive symptoms in early adolescence?. Does physical activity protect against depressive symptoms in early adolescence. Development of depressive symptoms in early adolescence. The youth and mental health study.. Trondheim: NTNU, 2004.

\section{Thomas 2004}

Thomas J, Harden A, Oakley A, Oliver S, Sutcliffe K, Rees R, et al. Integrating qualitative research with trials in systematic reviews. BMJ 2004;328:1010. [DOI: 10.1136/bmj.328.7446.1010] 


\section{Thomas 2008}

Thomas J, Harden A. Methods for the thematic synthesis of qualitative research in systematic reviews. BMC Medical Research Methodology 2008;8:Article number: 45. [DOI: 10.1186/1471-2288-8-45]

\section{Tidemalm 2008}

Tidemalm D, Waern M, Stefansson CG, Elofsson S, Runeson B. Excess mortality in persons with severe mental disorder in Sweden: a cohort study of 12,103 individuals with and without contact with psychiatric services. Clinical Practice and Epidemology in Mental Health 2008;4(23):1-9. [DOI: 10.1186/1745-0179-4-23; PMC2576252 ; PUBMED: 18854034]

\section{US Dept of HHS 2008}

US Department of Health and Human Services. Physical activity guidlines for Americans. Advisory Committee Report 2008. health.gov/paguidelines/2008/report/pdf/committeereport.pdf (accessed 24 January 2019).

\section{van Steensel 2011}

van Steensel FA, Bögels S, Perrin S. Anxiety disorders in children and adolescents with Autistic Spectrum Disorders: a meta-analysis. Clinical Child and Family Psychology Review 2011;14(3):302-17. [DOI: 10.1007/s10567-011-0097-0; PMC3162631; PUBMED: 21735077]

\section{Vancampfort 2015}

Vancampfort D, Stubbs B, Sineaert P, Wyckaert S, De Hert M, Rosenbaum $S$, et al. What are the factors that influence physical activity participation in individuals with depression? A review of physical activity correlates from 59 studies. Psychiatria Danubina 2015;27(3):210-24. [PUBMED: 26400128]

\section{Vancampfort 2017}

Vancampfort D, Firth J, Schuch FB, Rosenbaum S, Mugisha J, Hallgren M, et al. Sedentary behavior and physical activity levels in people with schizophrenia, bipolar disorder and major depressive disorder: a global systematic review and metaanalysis. World Psychiatry 2017;16(3):308-15. [DOI: 10.1002/ wps.20458; PMC5608847; PUBMED: 28941119]

\section{Wheeler 2018}

Wheeler AJ, Roennfeldt H, Slattery M, Krinks R, Stewart V. Codesigned recommendations for increasing engagement in structured physical activity for people with serious mental health problems in Australia. Health \& Social Care in the Community 2018;26(6):860-70. [DOI: 10.1111/hsc.12597; PUBMED: 30047608$]$

\section{WHO 1992}

World Health Organization. The ICD-10 classification of mental and behavioural disorders: clinical descriptions and diagnostic guidelines. Geneva: World Health Organization, 1992.

\section{WHO 2010}

World Health Organization. Global recommendations on physical activity for health. www.who.int/dietphysicalactivity/ publications/9789241599979/en/ (accessed 23 January 2019).

\section{WHO 2012}

World Health Organization. Recommended levels of physical activity for children aged 5-17 years. Global strategy on diet, physical activity and health. www.who.int/dietphysicalactivity/ factsheet_young_people/en/ (accessed 30 December 2019).

\section{WHO 2014}

World Health Organization. Social determinants of mental health. apps.who.int/iris/bitstream/ handle/10665/112828/9789? sequence=1 (accessed 23 January 2019).

\section{WHO 2017}

World Health Organization. Depression and other common mental disorders. Global health estimates. apps.who.int/ iris/bitstream/handle/10665/254610/WHO-MSD-MER-2017.2eng.pdf (accessed 26 January 2019).

\section{WHO 2018}

World Health Organization. WHO launches ACTIVE: a toolkit for countries to increase physical activity and reduce noncommunicable diseases. who.int/ncds/prevention/physicalactivity/active-toolkit/en/ (accessed 24 January 2019).

\section{Wilkinson 2019}

Wilkinson R, Pickett K. The inner level: how more equal societies reduce stress, restore sanity and improve everyone's well-being. London: Penguin Press, 2019.

\section{Wilmot 2012}

Wilmot EG, Edwardson CL, Achana FA, Davies MJ, Gorely LJ, Gray K, et al. Sedentary time in adults and the association with diabetes, cardiovascular disease and death: systematic review and meta-analysis. Diabetologia 2012;55(11):2895-905.

\section{Wright 2009}

Wright A, Cattan M. Physical activity and the management of depression. Working with Older People 2009;13(1):15-8. [DOI: 10.1108/13663666200900004]

\section{Wynaden 2012}

Wynaden D, Barr L, Omari O, Fulton A. Evaluation of service users' experiences of participating in an exercise programme at the Western Australian state forensic mental health services. International Journal of Mental Health Nursing 2012;21(3):229-35. [DOI: 10.1111/j.1447-0349.2011.00787.x; PUBMED: 22533330]

\section{Young 2017}

Young SJ, Praskova A, Hayward N, Patterson S. Attitudes to physical health in mental health services in Australia: a qualitative study of service users' experiences and expectations. Health \& Social Care in the Community 2017;25(2):602-11. [DOI: 10.1111/hsc.12349; PUBMED: 27093882]

\section{Yungblut 2012}

Yungblut HE, Schinke RJ, McGannon KR. Views of adolescent female youth on physical activity during early adolescence. $J$ Sport Sci Med 2012;11:39-50. 


\section{Zahl 2017}

Zahl T, Steinsbekk S, Wichstrøm L. Physical activity, sedentary behavior, and symptoms of major depression in middle childhood. Pediatrics 2017;139(2):e20161711. [DOI: 10.1542/ peds.2016-1711]

\section{AP P E N D I C E S}

\section{Appendix 1. MEDLINE search}

\section{Ovid MEDLINE(R) and Epub Ahead of Print, In-Process \& Other Non-Indexed Citations and Daily (1946 onwards)}

1. anxiety disorders/or agoraphobia/ or anxiety, separation/or neurocirculatory asthenia/ or neurotic disorders/or obsessive-compulsive disorder/ or hoarding disorder/ or panic disorder/ or phobia, social/

2. (anxiety disorder? or ADNOS or agoraphobi* or general ${ }^{\star}$ anxi ${ }^{\star}$ or GAD or separation anxiety or neurocirculatory asthenia or neurotic disorder? or obsessive compulsive or OCD or hoarding disorder? or panic or phobi ${ }^{\star}$ or (social* adj2 (anxi ${ }^{\star}$ or fear)) or mute? or mutism or (school adj2 (fear or refusal))).ti,ab,kf.

3. (anxi ${ }^{\star}$ adj2 (adult* or infant? or child ${ }^{\star}$ or adolesc ${ }^{\star}$ or p? ediatric ${ }^{\star}$ or teen ${ }^{\star}$ or young ${ }^{\star}$ or youth or school? or preschool ${ }^{\star}$ or middle age? or old age? or elder* or geriatri* or late* life)).ti,ab,kf.

4. (anxiety adj5 (autism or autistic)).ti,ab,kf.

5. anxiety.mp. and (child development disorders, pervasive/ or autism spectrum disorder/ or autistic disorder/)

6. anxiety.ti.

7. exp phobic disorders/

8. (aerophobi ${ }^{\star}$ or acrophobi $i^{\star}$ or arachnophobi ${ }^{\star}$ or claustrophobi ${ }^{\star}$ or cynophobi ${ }^{\star}$ or mysophobi ${ }^{\star}$ or ophidiophobi ${ }^{\star}$ or (fear adj2 (flying or flights or height? or spider? or snake? or dog? or ((small or restrict*) adj space?) or germ? or bacteri* or contaminat $\left.\left.{ }^{\star}\right)\right)$ ).ti,ab,kf.

9. (dentophobi ${ }^{\star}$ or h?emophobi ${ }^{\star}$ or trypanophobi ${ }^{\star}$ or aichmophobi* or (fear adj2 (dental or dentist? or blood ${ }^{\star}$ or injection? or needle?))).ti,ab,kf.

10. "trauma and stressor related disorders"/ or adjustment disorders/ or stress disorders, traumatic/ or combat disorders/ or psychological trauma/ or stress disorders, post-traumatic/ or stress disorders, traumatic, acute/

11. (acute stress or traumatic stress or (stress adj2 disorder?) or adjustment disorder? or combat disorder? or (psychological adj1 trauma*) or (posttrauma* adj1 stress*) or (post trauma* adj1 stress*) or PTSD).ti,ab,kf.

\section{Mood Disorders/}

13. depression/ or depressive disorder/ or depressive disorder, major/ or dysthymic disorder/

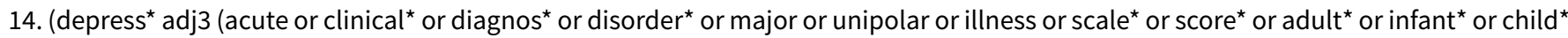
or adolesc ${ }^{\star}$ or p? ediatric ${ }^{\star}$ or teen* or young or youth? or middle age? or old age? or elder* or geriatri* or late ${ }^{\star}$ life or patient* or participant ${ }^{\star}$ or people or inpatient ${ }^{\star}$ or in-patient ${ }^{\star}$ or outpatient ${ }^{\star}$ or out-patient $\left.\left.{ }^{\star}\right)\right)$. ab.

15. (depress ${ }^{\star}$ and Beck* $^{*}$ or BDI $^{\star}$ or DSM $^{*}$ or (Statistical Manual adj2 Mental Disorders) or Hamilton or HAM-D or HAMD or MADRS or (International Classification adj2 Disease?) or ICD-10 or ICD-9)).ab.

16. "with depressi*".ab.

17. dysthymi*.ti,ab,kf.

18. (depress ${ }^{\star}$ or mood).ti,kf.

19. Seasonal Affective Disorder/

20. (seasonal affective disorder ${ }^{\star}$ or ((seasonal ${ }^{\star}$ or winter) adj3 (depress ${ }^{\star}$ or mood ${ }^{\star}$ or affective disorder ${ }^{\star}$ or affective symptom)) or SIGHSAD).ti,ab,kf

\section{Depressive Disorder, Treatment-Resistant/}

22. (depress ${ }^{\star}$ adj3 (refractor ${ }^{\star}$ or resistan ${ }^{\star}$ or chronic ${ }^{\star}$ or persist* or relaps $^{\star}$ or recurr $\left.^{\star}\right)$ ).ti,ab,kf.

\section{Depression, Postpartum/}

Factors that influence participation in physical activity for anxiety or depression: a synthesis of qualitative evidence (Protocol) 
24. ((postpartum ${ }^{\star}$ or post partum ${ }^{\star}$ or postnatal ${ }^{\star}$ or post natal ${ }^{\star}$ or perinatal ${ }^{\star}$ or peri natal ${ }^{\star}$ or puerp or intrapartum $^{\star}$ or intra partum $^{\star}$ or antepartum ${ }^{\star}$ or ante partum ${ }^{\star}$ or antenatal ${ }^{\star}$ or ante natal ${ }^{\star}$ or prenatal ${ }^{\star}$ or pre natal*) adj3 (depress ${ }^{\star}$ or adjustment disorder* or mood disorder ${ }^{\star}$ or affective disorder ${ }^{\star}$ or affective symptom $\left.{ }^{\star}\right)$ ).ti,ab,kf.

25. *mental disorders/

26. mental health/

27. *mentally ill persons/

28. (mental ${ }^{\star}$ adj2 (disorder? or health* or ill*)).ti.

29. or/1-28

30. ((access ${ }^{\star}$ or attitude? or barrier? or obstacle? or facilitat ${ }^{\star}$ or motiv ${ }^{\star}$ or preference? or predict ${ }^{\star}$ ) adj3 (exercis ${ }^{\star}$ or $\left(\right.$ physical $^{\star}$ adj (activit* or fit* or health)) or games or sport $\left.\left.{ }^{\star}\right)\right) . t i, a b, k f$.

31. (access ${ }^{\star}$ or attitude? or barrier? or obstacle? or facilitat ${ }^{\star}$ or motiv* or preference?).ti.

32. *Life Style/ or Healthy Lifestyle/ or *Health Behavior/ or Sedentary Behavior/

33. (health promotion or lifestyle intervention? or (promot* adj2 health*)).ti,ab,kf,sh.

34. Motivation/

35. or/31-34

36. exp Exercise/

\section{Exercise Therapy/}

\section{Physical Exertion/}

\section{Physical Fitness/}

40. Leisure Activities/

41. exp Recreation/

42. $\exp$ Sports/

43. (exercise or games or sport? or sporting or ((leisure or recreation $\left.{ }^{\star}\right)$ adj activ $\left.\left.{ }^{\star}\right)\right) . t i, a b, k f$.

44. (running or jogging or hopping or skipping or sprinting or park run? or treadmill? or treadmill?).ti,ab,kf.

45. (hiking or tramping or mountaineer $\left.{ }^{\star}\right) . t i, a b, k f, h w$.

46. (skiing? or snowboarding or snow boarding or iceskat* or ice skat* or skating).ti,ab,kf,hw.

47. bicycling.sh. or (bike? or biking or bicycl* or ((recreational or distance) adj cycling)).ti,ab,kf.

48. (water sports or ((aqua* or water) adj (activit* or fit $\left.\left.{ }^{\star}\right)\right)$ or swimming or sailing or boating or yachting or canoeing or kayaking or surfing or sailboard* or sail board $\left.{ }^{\star}\right)$.ti,ab,kf,hw.

49. (team game? or football ${ }^{\star}$ or rugby or cricket or rounders or baseball or netball or volleyball or tennis or squash or badminton).ti,ab,kf,hw.

50. (physical adj (activit* or conditioning or training)).ti,ab,kf.

51. ((weight? adj1 (lift* or train*)) or ((strength or resistance) adj training)).ti,ab,kf.

52. exercise movement techniques/ or breathing exercises/ or qigong/ or dance therapy/ or tai ji/ or yoga/ or kinesiology/

53. (qigong or qi gong or ch'i kung or Tai Chi or Taiji or Tai Chi Chuan or Taichi Quan or Taijiquan or Shadowboxing or Shadow Boxing or Tai Chi Chih or T'ai Chi Chuan or yoga or yogic or pilates or kinesiology).ti,ab,kf,ot.

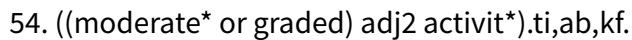

55. (aerobics or keep* fit or fitness training).ti,ab,kf. 
56. (walking or walks or pedomet ${ }^{\star}$ or fitbit? or fit bit? or ((fitness or activit $\left.{ }^{\star}\right)$ adj track $\left.{ }^{\star}\right)$ or (steps adj2 (count ${ }^{\star}$ or track $^{\star}$ or monitor $\left.\left.{ }^{\star}\right)\right)$ ).ti,ab,kf.

57. (ballet or dance or dancing or salsa or zumba).ti,ab,kf.

58. (gardening or horticultur* or allotment $^{\star}$ or ((nature or animal) adj2 therap*)).ti,ab,kf,hw.

59. Fitness Trackers/

60. "Physical Education and Training"/

61. fitness centers/

62. (gymnasium? or ((fitness or leisure or wellness) adj (cent* or facility or facilities))).ti,ab,kf.

63. ((activity adj2 (amount* or increas $^{\star}$ or level? or measur ${ }^{\star}$ or monitor $\left.{ }^{\star}\right)$ ) not (drug activity or active drug?)).ti.

64. (health promotion or lifestyle intervention?).ti,ab,kf,sh.

65. or/36-64

66. 29 and 30

67.29 and 35 and 65

68.66 or 67

69. exp animals/ not humans.sh.

70. (mice or mouse or murine or rat or rats or rodent ${ }^{\star}$ ).ti,kf.

71.68 not (69 or 70$)$

\section{Appendix 2. Data extraction template}

Data extraction template - qualitative synthesis

\section{Background Information}

\section{Author}

\section{Micro context: population}

(any specific characteristics, perspectives or subgroups?)

\section{Micro context: setting}

(setting e.g. hospital, private provider, timeframe of interest)

\section{Micro context: place}

(geographical location, political system e.g state-funded healthcare)

\section{Meso-context: intervention}

(description of intervention, recruitment, dose, duration, delivery)

\section{Macro-context}

(policy, political issues, social climate or legislation) 
(Continued)

\section{Data collection methods}

(e.g. focus group, face to face interviews, observation)

\section{Theory of change/logic model}

\section{Data analysis methods}

e.g. thematic analysis, grounded theory

\section{Relevant quantitative findings}

$\begin{array}{lll}\text { Purposive sampling category } & \begin{array}{l}\text { Popula- } \\ \text { tion }\end{array}\end{array}$ Diagnosis Methods $\begin{aligned} & \text { Interven- } \\ & \text { tion }\end{aligned} \quad$ Quality

\section{Participants}

\section{Sample size}

\section{Perspective}

Service users, carers, service providers, health professionals

$\begin{array}{lll}\begin{array}{l}\text { Service } \\ \text { users }\end{array} \quad \text { Carers } & \begin{array}{l}\text { Service } \\ \text { providers }\end{array} & \text { Health professionals }\end{array}$

\section{Modifying factors}

(for each participant category viewpoint: service user, carers, service providers, health professionals)

Age

\section{Socio-economic status (SES)}

Ethnicity

\section{Place of residence}

Occupation

\section{Education}

Social capital

\section{Primary diagnosis}

(list specific diagnosis)

\section{Co-morbidity}

\section{Severity}

\section{Length of condition}

\section{Perceived seriousness \& susceptibility}


(Continued)

Consideration of future

Self-identity

Perceived importance

Concern for appearance

Other perceptions of seriousness \& susceptibility

\section{Threats}

Perceived susceptibility - accepting mental health

diagnosis \& physical health needs

Perceived severity of mental health symptoms

Perceived physical health limits

Other threats

\section{Expectations}

Perceived benefits of physical activity

Perceived barriers to physical activity

Perceived self-efficacy - motivation, self-esteem

Other expectations

\section{Cues to Action}

Public health messages

Professionals

\section{Support networks}

Telemonitoring

\section{Other}

\section{Outcomes}

\section{Participation in physical activity}

Additional themes 


\section{CONTRIBUTIONS OF AUTHORS}

CMCC and JY conducted the initial literature review to prepare the protocol. JB, RC, GD and SG advised on the scope of the protocol. JB liaised with DRILL to request funding support. CMcC drafted the protocol. PB, GD, JF, BS, MT, PW and CW provided feedback on the protocol.

\section{DECLARATIONS OF INTEREST}

Claire J McCartan: no conflicts of interest

Jade Yap: no conflicts of interest

Paul Best: no conflicts of interest

Joseph Firth: is supported by a National Institute of Complementary Medicine (NICM) and Blackmores Institute Fellowship.

Mark A Tully: no conflicts of interest

Paul Webb: no conflicts of interest

Chris White: no conflicts of interest

Simon Gilbody: no conflicts of interest

Brendon Stubbs: no conflicts of interest

Rachel Churchill: leads and has responsibility for Cochrane Common Mental Disorders, which has supported parts of the review process and is largely funded by a grant from the National Institute for Health Research (NIHR) in the UK.

Josefien Breedvelt: no conflicts of interest

Gavin Davidson: is employed as the Praxis Chair of Social Care at Queen's University Belfast. This position is part funded by Praxis Care, a mental health service provider.

\section{SOURCES OF SUPPORT}

\section{Internal sources}

- Queen's University Belfast, UK.

- University of York, UK.

\section{External sources}

- Disability Research on Independent Living and Learning (DRILL), UK.

Funding was provided for CMcC's salary for 0.5 days per week over a three-month period to help complete this protocol.

- National Institute of Complementary Medicine (NICM) and Blackmores Institute, Australia.

JF is supported by a NICM-Blackmores Institute Fellowship

- Praxis Care, UK.

GD's post at Queen's University Belfast is part funded by Praxis Care 